\title{
Influence of Ground Calcium Carbonate Waste on the Properties of Green Self-Consolidating Concrete Prepared by Low-Quality Bagasse Ash and Rice Husk Ash
}

\author{
Pusit Lertwattanaruk ${ }^{1, *}$ and Natt Makul ${ }^{2}$ (D) \\ 1 Faculty of Architecture and Planning, Thammasat University, Pathumthani 12121, Thailand \\ 2 Faculty of Industrial Technology, Phranakhon Rajabhat University, Bangkok 10220, Thailand; natt@pnru.ac.th \\ * Correspondence: lertwatt@tu.ac.th
}

check for

updates

Citation: Lertwattanaruk, P.; Makul, N. Influence of Ground Calcium Carbonate Waste on the Properties of Green Self-Consolidating Concrete Prepared by Low-Quality Bagasse Ash and Rice Husk Ash. Materials 2021, 14, 4232. https://doi.org/ $10.3390 /$ ma14154232

Academic Editors: Dolores Eliche Quesada and Eddie Koenders

Received: 19 May 2021

Accepted: 26 July 2021

Published: 29 July 2021

Publisher's Note: MDPI stays neutral with regard to jurisdictional claims in published maps and institutional affiliations.

Copyright: (c) 2021 by the authors. Licensee MDPI, Basel, Switzerland. This article is an open access article distributed under the terms and conditions of the Creative Commons Attribution (CC BY) license (https:/ / creativecommons.org/licenses/by/ $4.0 /)$.

\begin{abstract}
Bagasse ash (BA) and rice husk ash (RHA) are by-products from electricity power plants. Ground calcium carbonate waste (GCW) is the by-product of the mining of calcium carbonate $\left(\mathrm{CaCO}_{3}\right)$ in the color pigment manufacturing industry. Both BA and RHA are classified as low-quality pozzolanic materials, differing from GCW, which contains a high calcium oxide $(\mathrm{CaO})$ content that leads to products equivalent to the hydration reaction. Therefore, GCW is likely able to improve the properties of self-consolidating concrete (SCC) incorporating BA and RHA. This paper discusses the production of green self-consolidating concrete (gSCC) and identifies the benefit of using GCW in gSCC prepared by triple combined GCW (10 and $20 \mathrm{wt} \%)$, BA $(10,20$, and $30 \mathrm{wt} \%)$, and RHA $(20 \mathrm{wt} \%)$. The results indicate that the majority of the gSCC retain acceptable flowability. The differences in the levels of gSCC substitution and the V-funnel flow results show general correlations with the increase in GCW. The gSCC prepared by $10 \mathrm{wt} \%$ GCW associated with $10 \mathrm{wt} \%$ BA and $20 \mathrm{wt} \%$ RHA was improved significantly. The filling and passing abilities of the gSCC were improved by using GCW. In addition, gSCC achieved mechanical property development and was able to minimize the consumption of OPC by up to $40 \%$.
\end{abstract}

Keywords: green self-consolidating concrete (gSCC); ground calcium carbonate waste (GCW); bagasse ash (BA); rice husk ash (RHA); workability; mechanical properties

\section{Introduction}

The cement industry is becoming a severe threat to ecology due to its emission of carbon dioxide $\left(\mathrm{CO}_{2}\right)$. The modern world is looking for alternatives so that the environment can be saved for the next generation [1-4]. To combat climate change, cement producers have tried to minimize the consumption of Portland cement through the application of supplementary cementitious materials, such as natural pozzolanic materials, to minimize emission of carbon dioxide $\left(\mathrm{CO}_{2}\right)$ and partly substitute Portland cement in concretes.

It is well known that pozzolanic materials play an important role when incorporated in concrete production using a reduced Portland cement content. One of the conventional pozzolanic materials is fly ash obtained from thermal power plants where coal, such as anthracite, bituminous and lignite, is used as fuel to generate electricity. This byproduct can potentially provide additional positive effects for concrete such as increased workability [5,6], especially for utilization in self-consolidating concrete (SCC), and also for the development of long-term compressive strength and other durability properties. Additionally, a by-product such as silica fume, originally obtained from the electric arc furnace of silicon metal or ferrosilicon alloys, can provide super-strength concrete at an early stage of hydration and pozzolanic reactions, as well as a filling effect from natural nanoscale particles. However, these materials are widespread in countries that have heavy industry such as the USA, China, and Germany. Import of these materials into other developing countries for use as raw materials in concrete production results in a higher 
cost of transportation. This critical issue causes other countries to pursue selective materials in local regions with lower costs of preparation for use as concrete-making materials.

One potential solution to low-cost replacement materials for Portland cement is to use the by-products from thermal power plants. In Southeast Asian countries such as Thailand, Malaysia, Vietnam, and Indonesia, biomass such as rice husk ash (RHA) [7,8], bagasse ash (BA) [9-11], and palm bunch are commonly used as fuel to generate electricity. The biomass ashes obtained as by-products are continuously increasing in quantity, causing waste disposal problems, air pollution, and contamination of soil and water resources [12] Nonetheless, biomass ashes are natural materials and have intrinsic variations, causing the by-products to be correspondingly varied in both chemical composition and physical properties, resulting in varying properties of the concrete. Biomass ash mainly consists of silicon dioxide $\left(\mathrm{SiO}_{2}\right)$, which is needed to react with calcium hydroxide $\left(\mathrm{Ca}(\mathrm{OH})_{2}\right)$ from the hydration reaction of Portland cement, but the large particles of biomass hinder the reactivity of the pozzolanic reaction. Thus, the cost of grinding for reducing the particle size of biomass ash becomes an essential factor and a limitation of the use of biomass ash as cementitious materials. Typically, thermal power plants only use biomass to produce heat to achieve a certain energy level needed, rather than having a production process that facilitates other ash utilization. This has a great effect on the combustion temperature of biomass in an incineration plant, resulting in the properties of biomass ash in the hydration reaction with Portland cement. In Thailand, BA is the main biomass ash used as a raw material in the production of SCC due to the fact that SCC is a type of high-performance concrete that conventionally consumes high-volume binder materials.

Bagasse ash (BA) is a by-product obtained from the combustion of bagasse for thermal power generation in the sugar manufacturing industry; it has of late been recognized as a low-quality pozzolanic material [2]. Therefore, most BA is still disposed of in landfills daily, resulting in ecological challenges in the world. BA received from the sugar industry needs a higher water content in the mixtures of concrete production because it has high porosity and large particle sizes, leading to a low compressive strength of the concrete [11]. The compressive strength of the concrete containing ground BA improves greatly when the BA is ground into fine particles. According to Clark et al. [3], fine or ground BA can be utilized as a substitute for up to $30 \%$ of the weight of ordinary Portland cement (OPC), and the 28-day and 90-day compressive strengths of concretes can be lower than those of concretes without BA. Thus, other biomass ashes such as rice husk ash (RHA) are also possible alternative cement replacement materials.

Rice husk ash (RHA) is a possible material for use in cement substitution to achieve these improvements. Rice husk ashes obtained from burning rice hull/husk to generate power can be utilized as a cementitious material partially replacing Portland cement in the production of SCC. RHA commonly consists of up to $25 \%$ of SCC composition, which meets the compressive strength for building code specifications and workability criteria of the European Federation of National Associations Representing for Concrete [13]. Selfconsolidating concretes normally require compressive strengths in the range of 28 to $35 \mathrm{MPa}$. Therefore, fine aggregate replacements have not reduced the costs of concrete production. Nevertheless, the incorporation of BA and RHA still has a limitation as Portland cement replacement materials. Furthermore, the utilization of the other fine filler materials can potentially improve the replacement rate of BA and RHA and also enhance the early-age and long-term properties of SCC. A better alternative is to use waste from another industry such as ground calcium carbonate waste (GCW) as a filler material to increase the efficiency of SCC concrete.

More than 10,000 tons of GCW, by-products of mining of calcium carbonate $\left(\mathrm{CaCO}_{3}\right)$ in the pigment manufacturing industry, are produced annually, and these amounts tend to increase each year [14]. The majority of these residues are disposed as wastes into the atmosphere, resulting in environmental challenges to landfills since there is only a small likelihood of their application in other uses. Subsequently, trials have attempted to utilize calcium carbonate in other applications, particularly in concrete uses [15]. It was revealed 
that mixtures of pozzalan material with a high calcium oxide $(\mathrm{CaO})$ content and GCW that is rich in calcium hydroxide $\left(\mathrm{Ca}(\mathrm{OH})_{2}\right)$ generate pozzolanic reactions, leading to end products equivalent to those produced from hydration processes of cement. According to Turuallo and Mallisa [12], mortars prepared from mixtures of fly ashes and GCW had compressive strengths of $20.9 \mathrm{MPa}$ at 90 days. By weight, the optimal ratio of fly ash to GCW was 70:30. Kerkhoff [16] investigated mortars having RHA and GCW. It was reported that the optimal ratio of RHA and GCW to accomplish the greatest potential compressive strengths was 50:50 wt $\%$. At one month, the mortar's compressive strength was $15.6 \mathrm{MPa}$ and improved to $19.1 \mathrm{MPa}$ at six months [9].

This research investigates the effect of GCW in green self-consolidating concrete (gSCC) prepared by triple combined bagasse ash (BA), rice husk ash (RHA), and GCW. The low-quality BA-and-RHA gSCC was improved by using GCW that has a greater availability than other supplementary cementitious materials. The gSCC mixtures of BA and RHA might be utilized to substitute OPC in concrete works. This can help in reducing the emission of $\mathrm{CO}_{2}$ due to the reduction in the production of Portland cement. This can also improve the values of waste substances instead of the alternative of transferring them to landfills where they cause air and soil pollutions.

\section{Materials and Methods}

\subsection{Materials}

\subsubsection{Ordinary Portland Cement (OPC)}

In this research, Type I Ordinary Portland cement (OPC) was introduced as the main cementing material complying with ASTM C150 [17]. This was carried out with a percentage replacement of up to $20 \mathrm{wt} \%$ of GCW to accelerate the reactions between ground BA and RHA. Tables 1 and 2 show, respectively, the physical properties and chemical components of OPC, BA, RHA and GCW.

Table 1. Physical properties and pozzolanic activity of the materials.

\begin{tabular}{ccccc}
\hline Materials & $\begin{array}{c}\text { Mean } \\
\text { Particle Size }(\boldsymbol{\mu m}) \\
(\text { Average } \pm \text { SD) }\end{array}$ & $\begin{array}{c}\text { Specific Gravity } \\
\text { (Average } \pm \text { SD) }\end{array}$ & $\begin{array}{c}\text { Retained on a 45 } \mu \mathrm{m} \\
\text { Sieve (No.325) (\%) } \\
\text { (Average } \pm \text { SD) }\end{array}$ & $\begin{array}{c}\text { Pozzolanic Actvity } \\
\text { (mg CaO/g Sample) } \\
\text { (Average } \pm \text { SD) }\end{array}$ \\
\hline OPC & $14.61 \pm 1.38$ & $3.14 \pm 0.02$ & $3.53 \pm 0.98$ & None \\
BA & $25.70 \pm 4.22$ & $2.27 \pm 0.01$ & $14.53 \pm 1.02$ & $179.44 \pm 8.24$ \\
RHA & $17.31 \pm 2.56$ & $2.32 \pm 0.01$ & $10.06 \pm 3.11$ & $433.29 \pm 1.39$ \\
GCW & $3.02 \pm 0.26$ & $2.42 \pm 0.01$ & $1.12 \pm 0.34$ & $512.85 \pm 10.26$ \\
\hline
\end{tabular}

Table 2. Chemical components of OPC, BA, RHA, and GCW.

\begin{tabular}{ccccc}
\hline $\begin{array}{c}\text { Chemical Components } \\
\text { (\% by mass) }\end{array}$ & $\begin{array}{c}\text { OPC } \\
\text { (Mean } \pm \text { SD) }\end{array}$ & $\begin{array}{c}\text { BA } \\
\text { (Mean } \pm \text { SD) }\end{array}$ & $\begin{array}{c}\text { RHA } \\
\text { (Mean } \pm \text { SD) }\end{array}$ & $\begin{array}{c}\text { GCW } \\
\text { (Mean } \pm \text { SD) }\end{array}$ \\
\hline Loss on ignition $(\mathrm{LOI})$ & $0.92 \pm 0.05$ & $19.62 \pm 3.06$ & $6.31 \pm 0.72$ & $36.16 \pm 2.11$ \\
Sulfur tri-oxide $\left(\mathrm{SiO}_{3}\right)$ & $2.72 \pm 0.02$ & $2.27 \pm 0.23$ & $0.03 \pm 0.01$ & $0.12 \pm 0.02$ \\
Potassium oxide $\left(\mathrm{K}_{2} \mathrm{O}\right)$ & $0.31 \pm 0.01$ & $1.21 \pm 0.19$ & $1.34 \pm 0.03$ & $0.11 \pm 0.01$ \\
Sodium oxide $\left(\mathrm{Na}_{2} \mathrm{O}\right)$ & $0.22 \pm 0.01$ & $0.25 \pm 0.02$ & $0.12 \pm 0.01$ & $0.21 \pm 0.01$ \\
Magnesium oxide $(\mathrm{MgO})$ & $1.26 \pm 0.02$ & $0.93 \pm 0.04$ & $0.30 \pm 0.02$ & $1.72 \pm 0.03$ \\
Calcium oxide $(\mathrm{CaO})$ & $65.83 \pm 3.82$ & $11.49 \pm 1.87$ & $0.92 \pm 0.04$ & $56.53 \pm 8.19$ \\
32Iron oxide $\left(\mathrm{Fe}_{2} \mathrm{O}_{3}\right)$ & $3.44 \pm 0.12$ & $4.12 \pm 0.32$ & $0.14 \pm 0.01$ & $0.98 \pm 0.07$ \\
Aluminum oxide $\left(\mathrm{Al}_{2} \mathrm{O}_{3}\right)$ & $4.78 \pm 0.06$ & $5.16 \pm 0.44$ & $0.47 \pm 0.02$ & $0.42 \pm 0.06$ \\
Silicon dioxide $\left(\mathrm{SiO}_{2}\right)$ & $21.99 \pm 2.35$ & $55.06 \pm 5.23$ & $91.42 \pm 6.81$ & $4.38 \pm 0.18$ \\
\hline
\end{tabular}

\subsubsection{Bagasse Ash (BA)}

In this research, the BA utilized was obtained from the sugar industry, in which it was burned at temperatures of $800-850{ }^{\circ} \mathrm{C}$ and under an oxygen content of $34.5 \%$ in the burning chamber to produce electricity. The original BA was unsuitable for applications 
as low-reactivity pozzolanic materials in concretes because of their high porosity and large particle sizes. Chao and Kuo [2] and Clark et al. [3] revealed that the filler effects and pozzolanic activities of industrial ashes depend on their fineness and particle size. Therefore, using a Los Angeles grinding machine (ELE International, Bedfordshire United Kingdom) for $3.0 \mathrm{~h}$ at a rotating speed of $33.0 \mathrm{rpm}$, the original BA was dried to reduce their moisture contents to about $1.0-2.0 \%$ (dry basis) and was ground until the particles were less than $15 \%$ by mass and retained on a 45 micrometer $(\mu \mathrm{m})$ sieve. In addition to the BA, as-received RHA was the main by-product obtained from the electricity power plant that only used rice husk as fuel in the central part of Thailand. Its burning temperature was in the range of $650-680^{\circ} \mathrm{C}$ under an oxygen content of $65.5 \%$ in the burning chamber.

Table 1 shows the physical properties of OPC, ground BA, RHA and GCW. The pozzolanic activity by a Chapelle test of the materials ( $\mathrm{mg} \mathrm{CaO} / \mathrm{g}$ sample) was also presented. Mean particle sizes of the materials were tested 3 times each using a laser particle analyzer (Malvern Panalytical Ltd., Malvern, UK). BA has a mean particle size of $25.70 \mu \mathrm{m}$ and is larger than the other materials. Specific gravity and percentage retained on a $45 \mu \mathrm{m}$ sieve (No.325) were performed in accordance with ASTM C188 [18] and ASTM C430 [19], respectively. BA has a specific gravity of 2.27. The percentage retained on a $45 \mu \mathrm{m}$ sieve of BA particles was $14.53 \%$ by mass, higher than that of the other materials. The particle image of ground BA is irregular compared to those of OPC, RHA, and GCW, as shown in Figure 1.
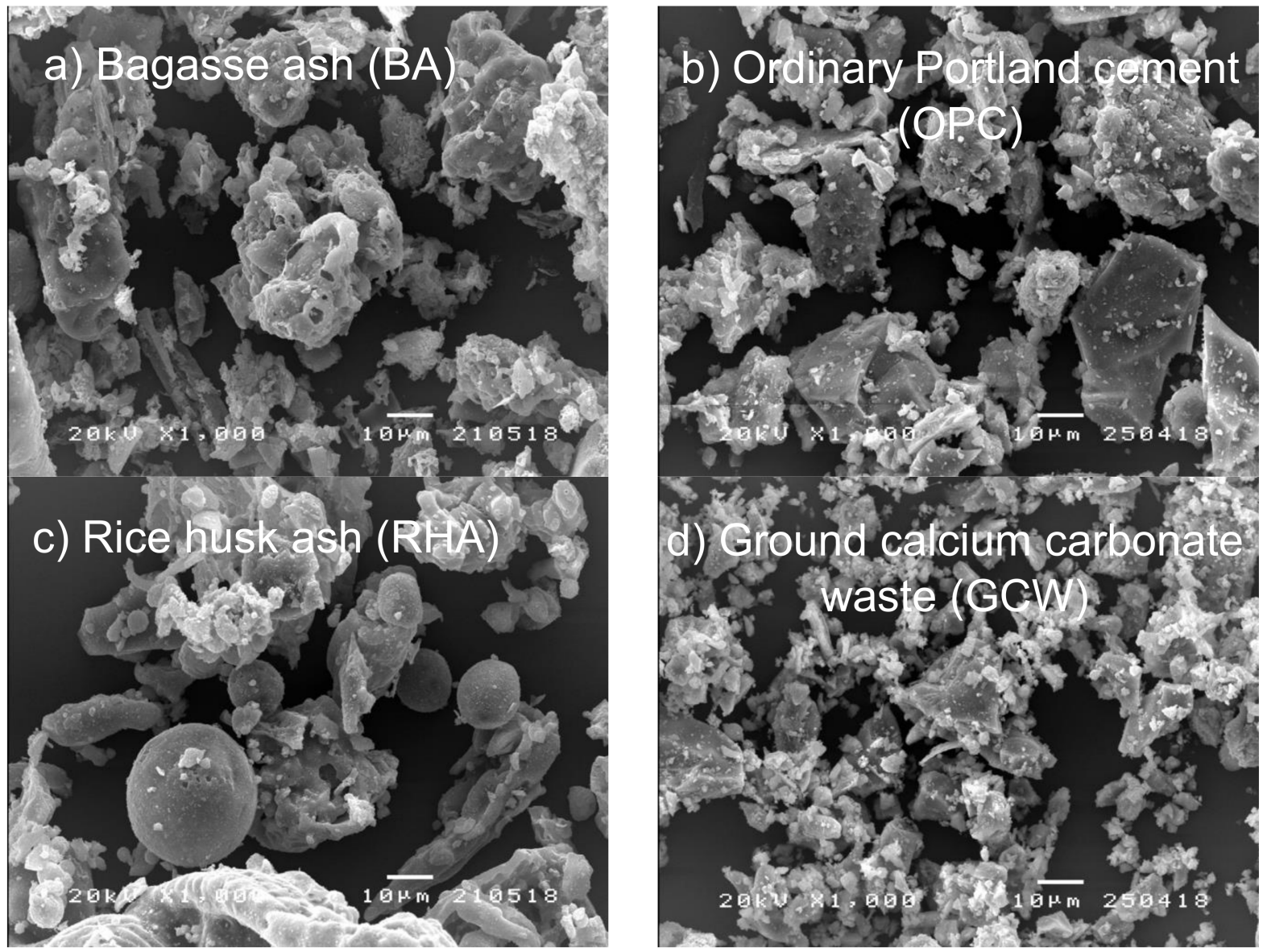

Figure 1. Scanning electron micrographs $(1000 \times)$ of (a) BA, (b) OPC, (c) RHA, and (d) GCW.

Table 2 shows the chemical components of ground BA, RHA and GWC obtained from $X$-ray fluorescence spectroscopy. While the $\mathrm{SO}_{3}$ and $\mathrm{LOI}$ amounts were $2.27 \%$ and $19.62 \%$, respectively, the total quantities of $\mathrm{Fe}_{2} \mathrm{O}_{3}, \mathrm{SiO}_{2}$, and $\mathrm{Al}_{2} \mathrm{O}_{3}$ were $64.20 \%$, and the main chemical composition of $\mathrm{BA}$ was $64.34 \%$ of $\mathrm{SiO}_{2}$. For a class $\mathrm{N}$ pozzolan, it was 
acknowledged that the LOI of ground BA was greater than the limit values outlined by ASTM C618 [20].

\subsubsection{Rice Husk Ash (RHA)}

At domestic biomass power generating plants, the dust collectors collected RHA that was similar in size. The RHA was used as treated using a Los Angeles grinding machine for $3.0 \mathrm{~h}$ at a rotating speed of $33 \mathrm{rpm}$. The RHA had a high content of silicon oxides $\left(\mathrm{SiO}_{2}\right)$. By mass percentages, this should be 91.42 as the X-ray fluorescences (XRFs) detected, as indicated in Table 2. Moreover, the 50\% passing particle size of RHA was $17.31 \mu \mathrm{m}$, which makes the RHA particles larger than the OPC particles.

\subsubsection{Ground Calcium Carbonate Waste (GCW)}

GCW is a by-product of the grinding processes of $\mathrm{CaCO}_{3}$. It has a high content of water [2]. As-received GCWs were dried to reduce their moisture content to about 1.0-2.0\% (dry basis) for about 1 day. Using the grinding machine, the calcium carbide residues were ground until the particles were less than $10.06 \%$ by mass and retained on a $45.0 \mu \mathrm{m}$ sieve (No. 325). Table 1 shows the physical characteristics of the GCWs. The GCWs had a mean particle size of $3.02 \mu \mathrm{m}$ and a specific gravity of 2.42. On a $45 \mu \mathrm{m}$ sieve (No. 325), the percentage of particles retained was $5.12 \%$ by mass. The GCW had a shape with irregular particles, as indicated in Figure 1. Table 2 reports the chemical components of the GCWs, which consist of $56.53 \%$ calcium oxide $(\mathrm{CaO})$, which is the main chemical component of the GCWs. Additionally, the LOI of GCWs was $36.16 \%$, which was high compared to other powder materials and in accordance with the study of Hoshino et al. [4], due to the fact that the $\mathrm{LOI}$ test was assessed by heating the sample to at least $950{ }^{\circ} \mathrm{C}$, and $\mathrm{CaCO}_{3}$ decomposes to calcium oxide $(\mathrm{CaO})$ and $\mathrm{CO}_{2}$ at temperatures above $750^{\circ} \mathrm{C}$.

\subsubsection{Aggregates}

In this study, the coarse aggregates were crushed limestone with a water absorption of $0.40 \%$, a fineness modulus of 7.20 , a specific gravity of 2.70 , and a maximum size of $19.0 \mathrm{~mm}$, which indicated a suitable gradation as specified in ASTM C33 [21]. The local river sands were the fine aggregates with water absorption of $0.80 \%$, a fineness modulus of 3.20, and a specific gravity of 2.60, complying with a gradation as specified in ASTM C33 [21].

\subsection{Mix Proportions of Green Self-Consolidating Concrete ( $g S C C)$}

Table 3 summarizes the mix proportions for the concretes for this research. All the mixtures of gSCCs were developed with the ratios of the water-binder materials of the control SCC at 0.40 by mass and computed with constant aggregate materials (sand + ground limestone rock). The total binder content (OPC/BA/RHA/GCW) was $650 \mathrm{~kg} / \mathrm{m}^{3}$. Depending on the targeted slump flow criteria, the $\mathrm{w} / \mathrm{b}$ ratios of the $\mathrm{gSCC}$ mixtures were varied, with the specific high-range water-reducing agent (HRWR at a concentration of $45.5 \%$ ) at $2.04 \%$ per $100 \mathrm{~kg}$ of binder materials, which was needed to obtain the target slump flows and $70.0 \pm 2.5 \mathrm{~cm}$ [13]. OPC was substituted with BA, with cement replacements of 10,20 , and $30 \mathrm{wt} \%$ and RHA of $20 \mathrm{wt} \%$ incorporating GCW used at cement replacements of 10 and $20 \mathrm{wt} \%$. 
Table 3. Mix proportions of gSCC.

\begin{tabular}{|c|c|c|c|c|c|c|c|c|c|}
\hline Mixture & $\begin{array}{l}\text { Binder } \\
\left(\mathrm{kg} / \mathrm{m}^{3}\right)\end{array}$ & $\begin{array}{c}\text { OPC } \\
\left(\mathrm{kg} / \mathrm{m}^{3}\right)\end{array}$ & $\begin{array}{c}\text { BA } \\
\left(\mathrm{kg} / \mathrm{m}^{3}\right)\end{array}$ & $\begin{array}{c}\text { RHA } \\
\left(\mathrm{kg} / \mathrm{m}^{3}\right)\end{array}$ & $\begin{array}{c}\text { GCW } \\
\left(\mathrm{kg} / \mathrm{m}^{3}\right)\end{array}$ & $\begin{array}{c}\text { Sand } \\
\left(\mathrm{kg} / \mathrm{m}^{3}\right)\end{array}$ & $\begin{array}{l}\text { Crushed } \\
\text { Limestone } \\
\left(\mathrm{kg} / \mathrm{m}^{3}\right)\end{array}$ & $w / b$ & $\begin{array}{c}\text { HRWR } \\
(\%)\end{array}$ \\
\hline $\begin{array}{c}\text { B0R0G0 [1] } \\
\text { (Control SCC) }\end{array}$ & 650 & 650 & 0 & 0 & 0 & 737 & 657 & 0.40 & 2.04 \\
\hline B10R0G0 & 650 & 585 & 65 & 0 & 0 & 737 & 657 & 0.48 & 2.04 \\
\hline B20R0G0 & 650 & 520 & 130 & 0 & 0 & 737 & 657 & 0.50 & 2.04 \\
\hline B30R0G0 & 650 & 455 & 195 & 0 & 0 & 737 & 657 & 0.54 & 2.04 \\
\hline B0R20G0 & 650 & 520 & 0 & 130 & 0 & 737 & 657 & 0.45 & 2.04 \\
\hline B10R20G0 & 650 & 455 & 65 & 130 & 0 & 737 & 657 & 0.49 & 2.04 \\
\hline B20R20G0 & 650 & 390 & 130 & 130 & 0 & 737 & 657 & 0.51 & 2.04 \\
\hline B30R20G0 & 650 & 325 & 195 & 130 & 0 & 737 & 657 & 0.56 & 2.04 \\
\hline B0R20G10 & 650 & 455 & 0 & 130 & 65 & 737 & 657 & 0.42 & 2.04 \\
\hline B10R20G10 & 650 & 390 & 65 & 130 & 65 & 737 & 657 & 0.45 & 2.04 \\
\hline B20R20G10 & 650 & 325 & 130 & 130 & 65 & 737 & 657 & 0.48 & 2.04 \\
\hline B30R20G10 & 650 & 260 & 195 & 130 & 65 & 737 & 657 & 0.49 & 2.04 \\
\hline B0R20G20 & 650 & 390 & 0 & 130 & 130 & 737 & 657 & 0.43 & 2.04 \\
\hline B10R20G20 & 650 & 325 & 65 & 130 & 130 & 737 & 657 & 0.44 & 2.04 \\
\hline B20R20G20 & 650 & 260 & 130 & 130 & 130 & 737 & 657 & 0.45 & 2.04 \\
\hline B30R20G20 & 650 & 195 & 195 & 130 & 130 & 737 & 657 & 0.47 & 2.04 \\
\hline
\end{tabular}

Remarks: ${ }^{[1]}$ BXRYCZ denotes the following: BX is the percentage OPC replacement of the BA content $(0,10,20$, and.30 $\mathrm{wt} \%), \mathrm{RY}$ is the percentage OPC replacement of the RHA content ( 0 and $20 \mathrm{wt} \%)$, and GZ is the percentage OPC replacement of GCW $(0,10$, and $20 \mathrm{wt} \%)$.

\subsection{Sample Preparation and Testing}

\subsubsection{Workability of gSCC}

The fresh gSCCs were made by applying revolving drum-type mixers (Siam Intercorp (Thailand) Co., Ltd., Bangkok, Thailand) for fifteen minutes in this research [15]. To achieve a $70.0 \pm 2.5 \mathrm{~cm}$ slump flow with fresh SCCs, the practical requirements are specified more clearly than those for ordinary fresh concretes. After mixing, the workability was promptly measured, which took place over a period of almost ten minutes. Based on two major abilities, the differences can be summarized:

- Filling ability: The concrete's ability to fully fill the formworks and deform under its weight while maintaining homogeneity is known as the filling ability. Using ASTM C1611 [22], the filling ability was estimated.

- Passing ability: The concrete's ability to flow via a confined area without overcrowding due to aggregate concretes is known as the passing ability. The concretes were tested using J-Rings to analyze the blocking behaviors and the passing ability of SCCs according to ASTM C1621 [23].

\subsubsection{Mechanical Properties}

From all typical batches of SCCs, 21 cylinders of $30.0 \mathrm{~cm}$ in height and $15.0 \mathrm{~cm}$ in diameter were cast. The molded samples were stored in a room at $95 \pm 5 \%$ relative humidity (RH) and at a temperature of $25 \pm 2{ }^{\circ} \mathrm{C}$ after they were covered with a plastic sheet after casting for one day. In lime-saturated water, the SCC samples were demolded after placing and compacting them for $24 \mathrm{~h}$ and they were continuously cured by soaking in tap water at $25^{\circ} \mathrm{C}$ until testing at $7,28,60,120,180,270$, and 360 days. The test results recorded were the averaged results obtained using three similar samples. As specified in ASTM C39 [24], ASTM C496 [25], and ASTM C469 [26], compressive strength, splitting tensile strength, and modulus of elasticity (MOE) were determined, respectively. 


\section{Results and Discussions}

\subsection{Physical Properties of Fresh gSCC}

3.1.1. Water Requirements Regarding w/b for Accomplishing gSCC

The gSCC mixtures with GCW incorporating different amounts of BA and RHA required a low $\mathrm{w} / \mathrm{b}$ ratio as compared to without GCW, but higher than the control SCC, in order to sustain the required slump flows. It was noted that the $\mathrm{w} / \mathrm{b}$ ratio for the gSCC mixtures incorporating BA varied in the range of 0.48 and 0.54 ; for the mixtures of gSCC with BA and RHA, it varied from 0.49 and 0.56 , and the $\mathrm{w} / \mathrm{b}$ ratio requirements for the gSCCs with BA and RHA incorporating GCW varied from 0.42 and 0.49 . The lower SCC $\mathrm{w} / \mathrm{b}$ ratio was due to the finer particle sizes of GCW and the larger specific surface areas. The required $\mathrm{w} / \mathrm{b}$ ratio conversely declines when the particles of GCW dissolve in the water. This can improve the lubrication or viscosity of the SCC mixtures in order to achieve suitable flow slumps. Moreover, the distribution of smaller particle sizes improves the mixture viscosity, while the higher distribution of particle sizes improves with declining viscosity. This is because the improved OPC + GCW or OPC contents decrease the amounts of water required. Therefore, the $\mathrm{w} / \mathrm{b}$ ratio is nearly constant. In summary, while maintaining the ability to flow, an increasing quantity of binder materials leads to high viscosity. For this reason, a lower $\mathrm{w} / \mathrm{b}$ ratio can improve some mechanical properties. The required $w / b$ ratio for the gSCC with BA and RHA was greater than that for SCCs without RHA, due to the high RHA particle porosity. Nevertheless, the mixtures of gSCCs with GCW achieved greater viscosity than the gSCCs mixed with BA and RHA.

\subsubsection{Fresh Density}

Table 4 shows the workability of the gSCC mixtures. In gSCC mixed with GCW, the fresh densities of the gSCC mixtures incorporating BA and RHA were decreased with a GCW content of $10 \mathrm{wt} \%$ (B0R20G10, B10R20G10, B20R20G10, and B30R20G10). The fresh densities of SCCs with GCW of $10 \mathrm{wt} \%$ (B30R20G10) and $20 \mathrm{wt} \%$ (B30R20G20) for the gSCC mixtures mixed with BA-RHA were $-4.42 \%$ and $-5.50 \%$, respectively, compared to the control gSCC (B0R0G0). This is because of the lower specific gravity of GCW (2.42). For GCW (10 wt \%), the fresh density of gSCCs with 10 and $20 w t \%$ BA and $20 w t \%$ RHA decreased by $-0.96 \%$ and $-2.11 \%$, respectively. This is because BA and RHA are coarser than the OPC, but this compensated for the additional GCW filling the spaces among the OPC particles [27]. 
Table 4. Workability of the gSCC mixtures.

\begin{tabular}{|c|c|c|c|c|c|c|c|c|}
\hline \multirow[b]{2}{*}{ Mixture } & \multirow{2}{*}{$\begin{array}{l}\text { Targeted } \\
\text { Flow Slump } \\
\quad(\mathrm{cm})\end{array}$} & \multirow{2}{*}{$\begin{array}{l}\mathrm{T}_{50} \\
(\mathrm{~s})\end{array}$} & \multirow{2}{*}{$\begin{array}{c}\mathrm{J}-\text { Ring Test } \\
\text { (Initial) } \\
\text { (cm) }\end{array}$} & \multirow{2}{*}{$\begin{array}{l}\text { Difference } \\
\text { (Initial) } \\
\text { (cm) }\end{array}$} & \multirow[b]{2}{*}{$\begin{array}{c}\text { Blocking } \\
\text { Assessment }\end{array}$} & \multirow{2}{*}{$\begin{array}{l}\text { V-Funnel } \\
\text { Flow Time } \\
\text { (s) }\end{array}$} & \multicolumn{2}{|c|}{ Fresh Density } \\
\hline & & & & & & & $\begin{array}{c}\text { Value } \\
\left(\mathrm{kg} / \mathrm{m}^{3}\right)\end{array}$ & $\%$ Control \\
\hline B0R0G0 & 67.5 & 2 & 67.0 & 0.5 & Not visible & 6 & 2483.2 & 100.00 \\
\hline B10R0G0 & 65.5 & 3 & 63.5 & 2.0 & Not visible & 8 & 2454.6 & -1.15 \\
\hline B20R0G0 & 65.0 & 4 & 62.5 & 2.5 & Noticeable & 18 & 2425.9 & -2.31 \\
\hline B30R0G0 & 63.5 & 5 & 58.0 & 5.5 & $\begin{array}{l}\text { Extreme } \\
\text { blocking }\end{array}$ & 45 & 2397.3 & -3.46 \\
\hline B0R20G0 & 66.5 & 4 & 64.5 & 2.0 & Not visible & 10 & 2427.2 & -2.26 \\
\hline B10R20G0 & 64.5 & 5 & 61.0 & 3.5 & Noticeable & 14 & 2398.5 & -3.41 \\
\hline B20R20G0 & 63.5 & 6 & 57.0 & 6.5 & $\begin{array}{l}\text { Extreme } \\
\text { blocking }\end{array}$ & 36 & 2369.9 & -4.56 \\
\hline B30R20G0 & 62.5 & 7 & 55.0 & 7.5 & $\begin{array}{l}\text { Extreme } \\
\text { blocking }\end{array}$ & 82 & 2341.3 & -5.72 \\
\hline B0R20G10 & 67.5 & 3 & 66.5 & 1.0 & Not visible & 8 & 2459.4 & -0.96 \\
\hline B10R20G10 & 67.0 & 5 & 65.5 & 1.5 & Not visible & 10 & 2430.8 & -2.11 \\
\hline B20R20G10 & 66.5 & 5 & 64.5 & 2.0 & Not visible & 11 & 2402.1 & -3.26 \\
\hline B30R20G10 & 66.0 & 6 & 62.5 & 3.5 & Noticeable & 12 & 2373.5 & -4.42 \\
\hline B0R20G20 & 66.5 & 2 & 64.5 & 2.0 & Not visible & 4 & 2432.5 & -2.04 \\
\hline B10R20G20 & 65.0 & 3 & 62.5 & 2.5 & Noticeable & 6 & 2403.9 & -3.19 \\
\hline B20R20G20 & 65.0 & 3 & 60.5 & 4.5 & Noticeable & 9 & 2375.3 & -4.35 \\
\hline B30R20G20 & 64.0 & 4 & 59.0 & 5.0 & Noticeable & 12 & 2346.6 & -5.50 \\
\hline
\end{tabular}

\subsubsection{Workability}

Table 4 shows the results of the initial slump flow test for all mixtures of gSCC compared to the control SCC. To maintain the fresh concrete slump, HRWR was added. It was reported that due to the particle sizes of BA and RHA being larger than those of the OPC particles, the GCW absorbed more moisture. For these reasons, the mixtures of gSCCs needed more HRWR than the control SCC [28,29]. Moreover, the higher loss on ignition (LOI) of GCW and BA caused an increase in the requirements of the $\mathrm{w} / \mathrm{b}$ ratio in the mixtures. In addition, the BA particles were characterized by a high porosity and were irregularly and angular shaped like RHA. For lubrication, gSCC prepared by BA needed a higher $\mathrm{w} / \mathrm{b}$ ratio to sustain similar workability as compared to that of the control SCC. Additionally, the results agree with the research of Ali and Al-Tersawy [28].

\section{Filling Ability}

The filling ability was indicated by the slump time and flow to achieve a slump flow of $50.0 \mathrm{~cm}$ in diameter, which represented the SCC deformation under their weights against the surface frictions with no restraint. The time taken by SCC mixtures to achieve a $50.0 \mathrm{~cm}$ diameter (the slump flow time, $\mathrm{T}_{50}$ ) is linked to the flow rates. From Table 4 , all the mixtures of the SCCs achieved an acceptable flow time that ranged from three to seven seconds. Using the GCW, the effect of the added GCW was to improve the gSCC viscosity due to incorporation of high-fineness particles generating a greater viscosity than the gSCC without GCW.

In mixtures with BA and RHA, the values of flow time were also measured. The addition of GCW in the mixtures helped in eliminating the mixing BA and RHA effects. With the higher GCW or lower OPC contents, the slump flow time decreased in the gSCC mixtures. This might be because of the smooth surfaces of the GCW that would increase the viscosity and inter-particle friction.

The V-funnel tests measured the time needed for SCCs to flow down via funnels. The V-funnel can be utilized to approximate the resistance to material segregations and the SCC paste viscosity. If the V-funnel time ranged between 8 and $12 \mathrm{~s}$, the resistance to segregation 
was considered satisfactory for the SCC mixtures tested [13]. The research findings and results show clear correlations between the obtained differences in the levels of calcium carbonate substitution and V-funnel flow time results. As the proportion of fine aggregates and total binder contents substituted by RHA increased, the flow time increased. All the gSCC mixtures incorporating the GCW achieved V-funnel values within satisfactory ranges. The GCW effects can be accredited to particle fineness and the shape characteristics of the binder materials. Compared with coarse binders, fine binder materials improve the values of spread flow. By contributing to an increase in the free water amount, the smooth surface textures of the GCW improved these behaviors, which are known to also improve cohesiveness and workability.

\section{Passing Ability}

The gSCC mixture with BA and RHA agglomeration and higher viscosity could cause higher visible blocking. Utilizing BA and RHA to substitute for OPC had significant effects on the SCC passing ability as well as the filling ability. The GCW greatly affected the passing ability. A precise trend and pattern is shown by the values of the mean J-ring flow. As the GCW and OPC increased, the passing ability also improved. As the content of GCW increased, the mixtures showed noticeable blocking. This is because the total volume of the binder that should go through the confined voids decreased as the paste volumes of the gSCC mixture increased, increasing the friction of the inter-particles among the BA and RHA. Equally, the applications of GCW as ternary blends to generate gSCC mixtures improved the viscosity and helped minimize blocking [10].

\subsection{Mechanical Properties}

\subsubsection{Compressive Strength}

Compared to control gSCC (B0R0G0), the compressive strengths of the developments of the gSCC mixtures that mixed RHA with GCW are shown in Figure 2. At 28 days, with the maximum rate of compressive strength development, B0R20G10 had compressive strengths of $62.41 \mathrm{MPa}$. This later improved to $85.03 \mathrm{MPa}$ and $97.13 \mathrm{MPa}$ at 180 and 360 days, respectively. However, for the highest compressive strength for the mixture mixed with BA, the substitution with BA at $10 \mathrm{wt} \%$ (B10R20G10) also developed in strength but at a lower rate compared to without BA (B0R20G10). Compared to the control gSCC (B0R0G0), the findings show that the applications of the mixtures of GCW with BA and RHA as binder content decreased the concrete's compressive strength at 360 days by about $28.85 \%$ (B10R20G10) and 32.41\% (B10R20G20). This might be credited to the fact the compressive strengths of the concretes were derived partly from the pozzolanic reaction of RHA and BA and enhanced by the reaction of GCW [28]. These results agree with the findings of Aydin et al. [30] and Atis et al. [31]. The scholars noted that the compressive strengths of mortars using the binder content from the mixtures of RHA and GCW appeared to improve with age of curing in a way similar to the developments of the compressive strengths of OPC.

The relationships between the compressive strengths and Portland cement substitution levels of BA/RHA/GCW in gSCC are indicated in Figure 3. The results show that utilizing $390 \mathrm{~kg} / \mathrm{m}^{3}$ of OPC (B10R20G10) as a catalyst yielded compressive strengths of $10.04 \mathrm{MPa}$ or $30.43 \%$ higher than those of B10R20G0 at 28 days. In general, a greater amount of OPC provides calcium hydroxide $\left(\mathrm{Ca}(\mathrm{OH})_{2}\right)$ and $\mathrm{C}-\mathrm{S}-\mathrm{H}$ (calcium silicate hydrates), resulting in better pozzolanic and hydration reactions [32,33]. As compared to the control gSCC, B10R20G10 needed as much as $65 \mathrm{~kg} / \mathrm{m}^{3}$ of GCW to achieve similar compressive strengths. The results and findings suggest that the applications of the mixtures of GCW and BA/RHA as binder materials might decrease the consumption of OPC by $40 \%$ [28]. Substituting $10 \%$ to $20 \%$ of the OPC was found to be optimal in comparison to the concretes integrating BA $[12,34]$. 


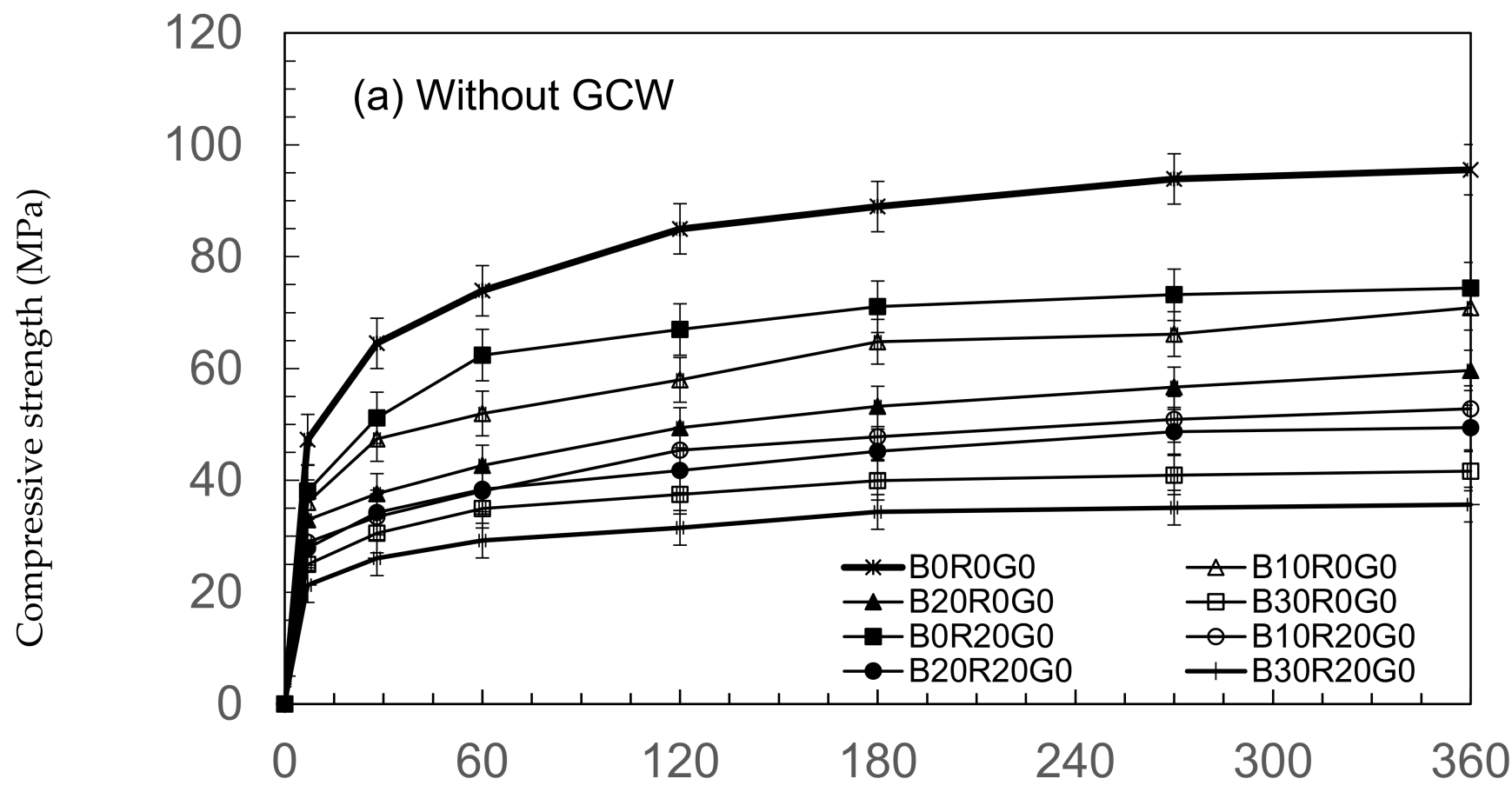

Curing time (days)

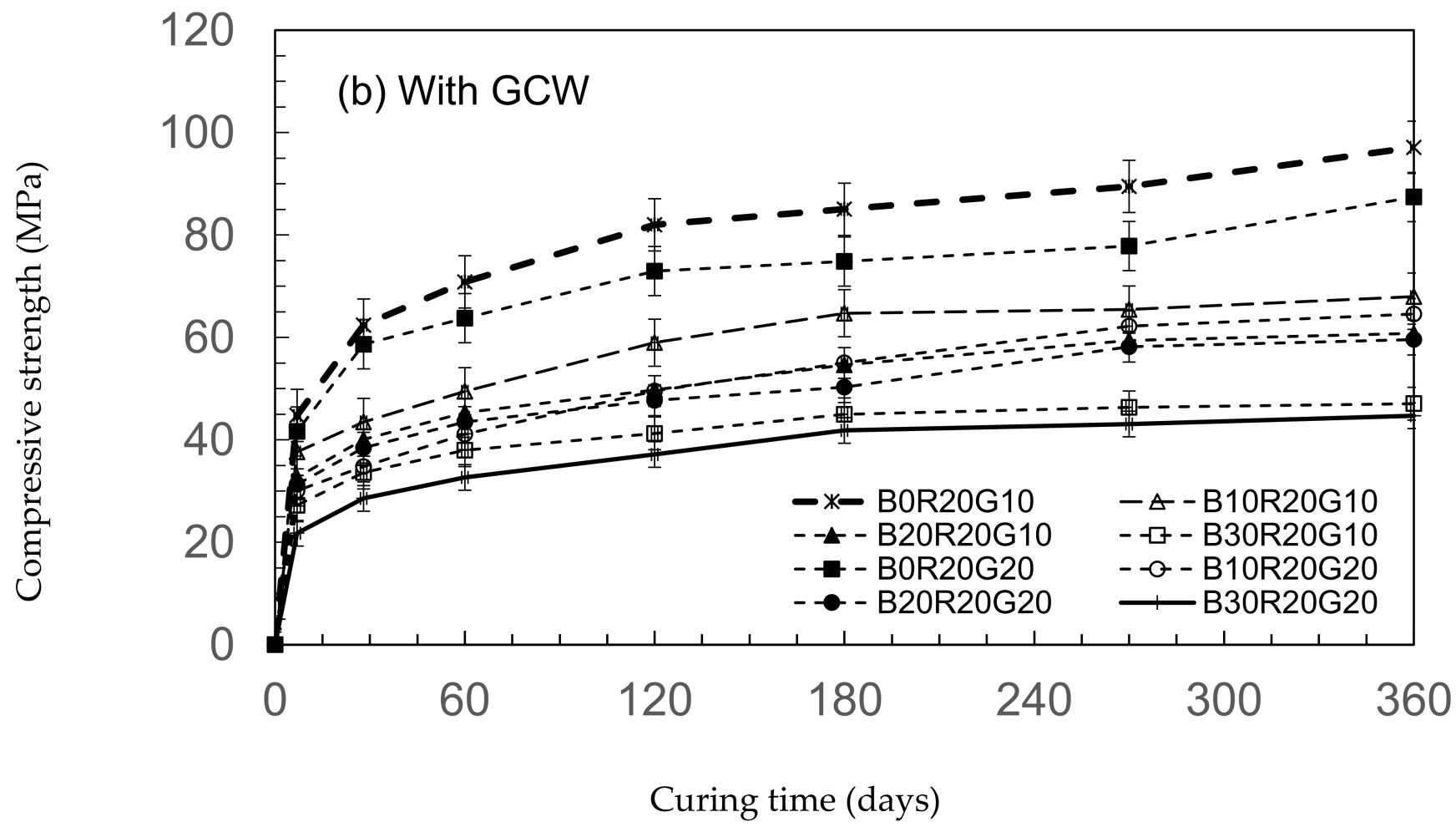

Figure 2. Compressive strengths of gSCC. (a) without GCW and (b) with GCW. 


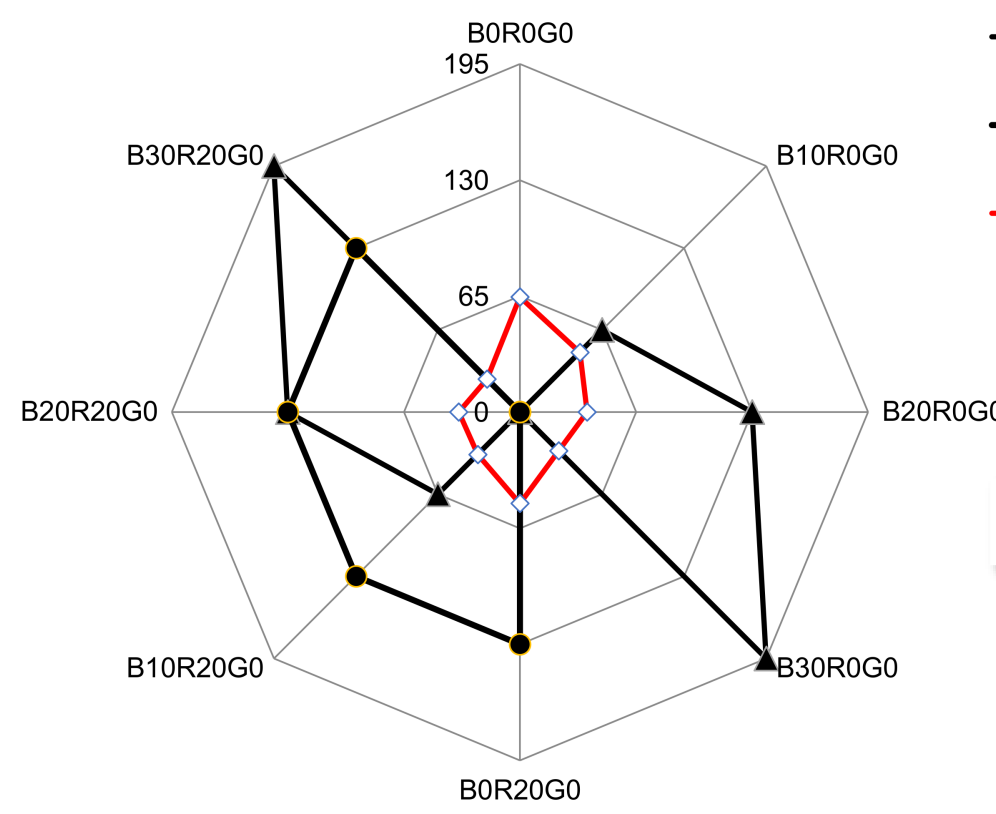

- -BA content $(\mathrm{kg} / \mathrm{m} 3)$

—॰-RHA content $(\mathrm{kg} / \mathrm{m} 3)$

$\neg$ Compressive strength at 28 days $(\mathrm{MPa})$

(a) Without GCW

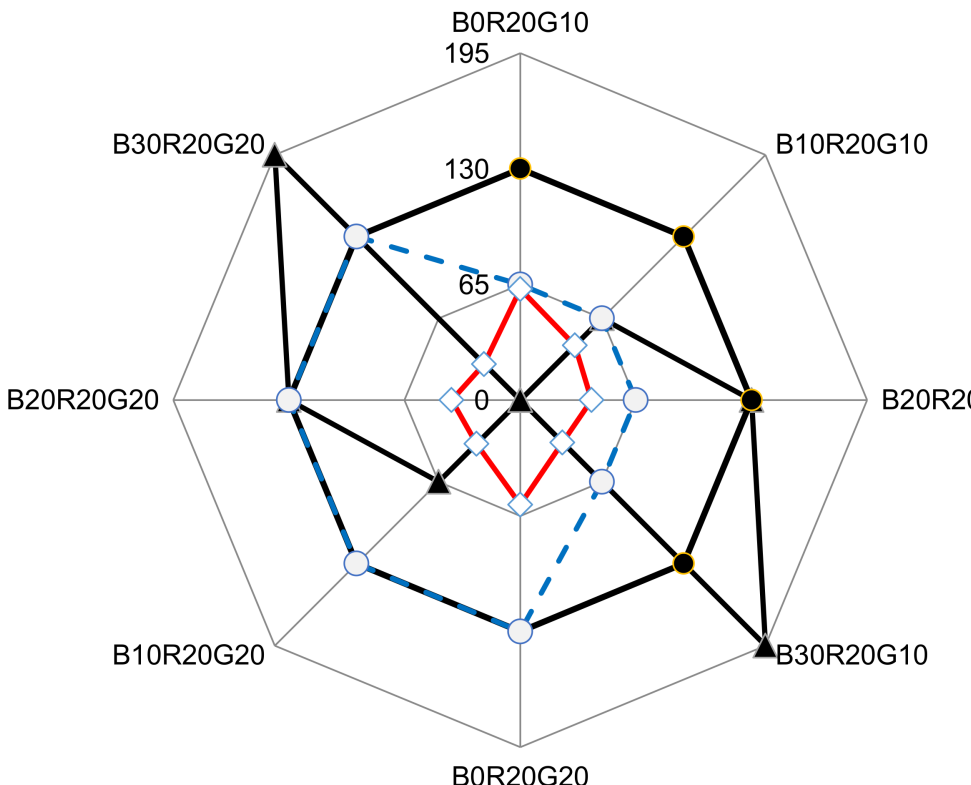

$\longrightarrow$ BA content $(\mathrm{kg} / \mathrm{m} 3)$

-

$-\circ-$ GCW content $(\mathrm{kg} / \mathrm{m} 3)$

$\longrightarrow$ Compressive strength at 28 days $(\mathrm{MPa})$

(b) With GCW

Figure 3. The relationships between compressive strengths of concretes and cement substitution levels of GCW, RHA, and BA in gSCC mixtures. (a) without GCW and (b) with GCW

\subsubsection{Splitting Tensile Strength}

With the improvement of compressive strengths, the splitting tensile strengths of B10R20G10 tended to improve compared to B10R20G0, as shown in Figure 4. These results show that the splitting tensile strengths are associated with the compressive strengths of the concretes [35]. The 28-day splitting tensile strength of B10R20G10, B20R20G10, and B30R20G10 were 43.5, 40.1, and 3.6 MPa, respectively. In addition, the splitting tensile strengths of gSCC tended to improve with all curing ages. 


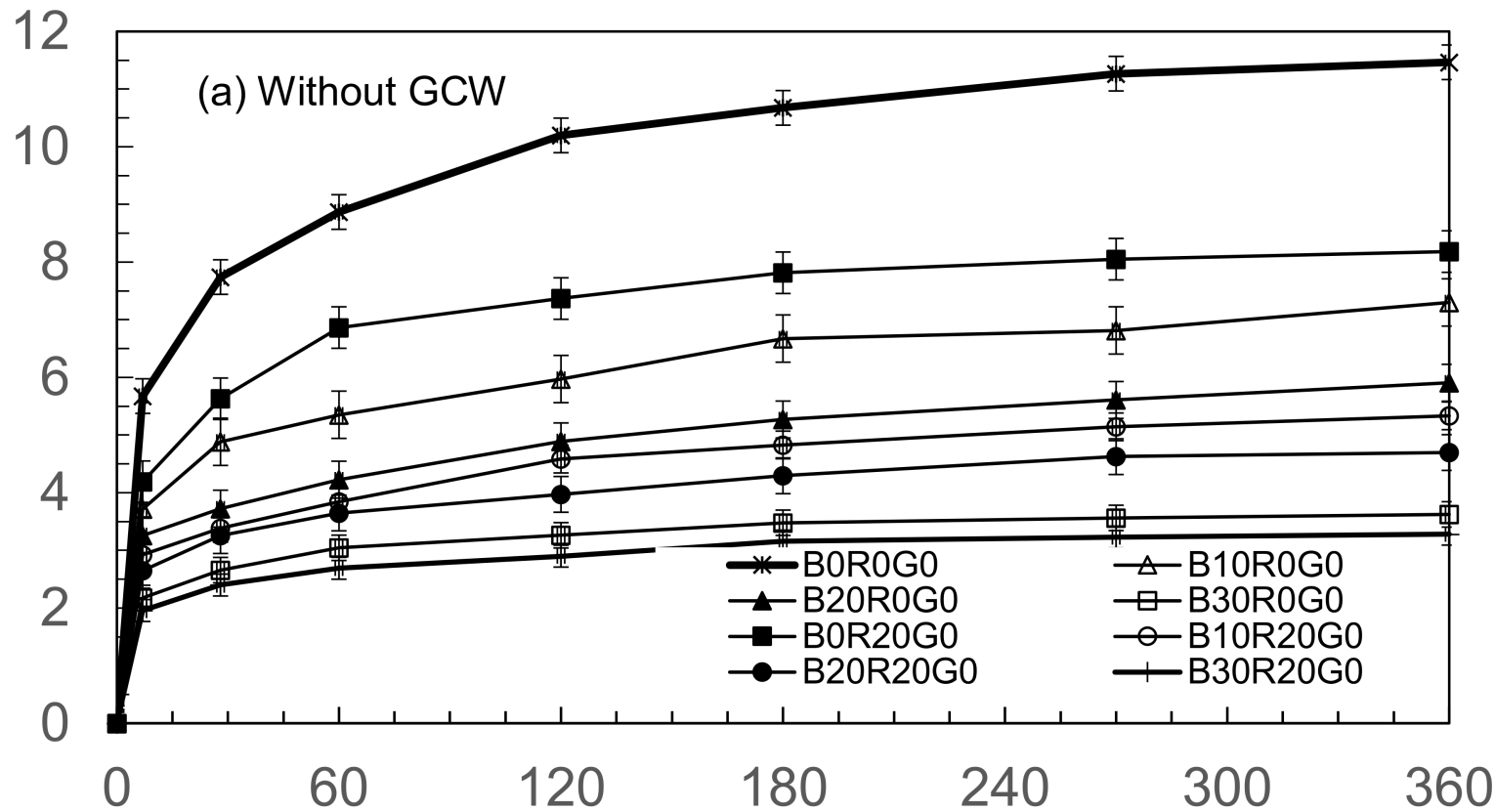

Curing time (days)

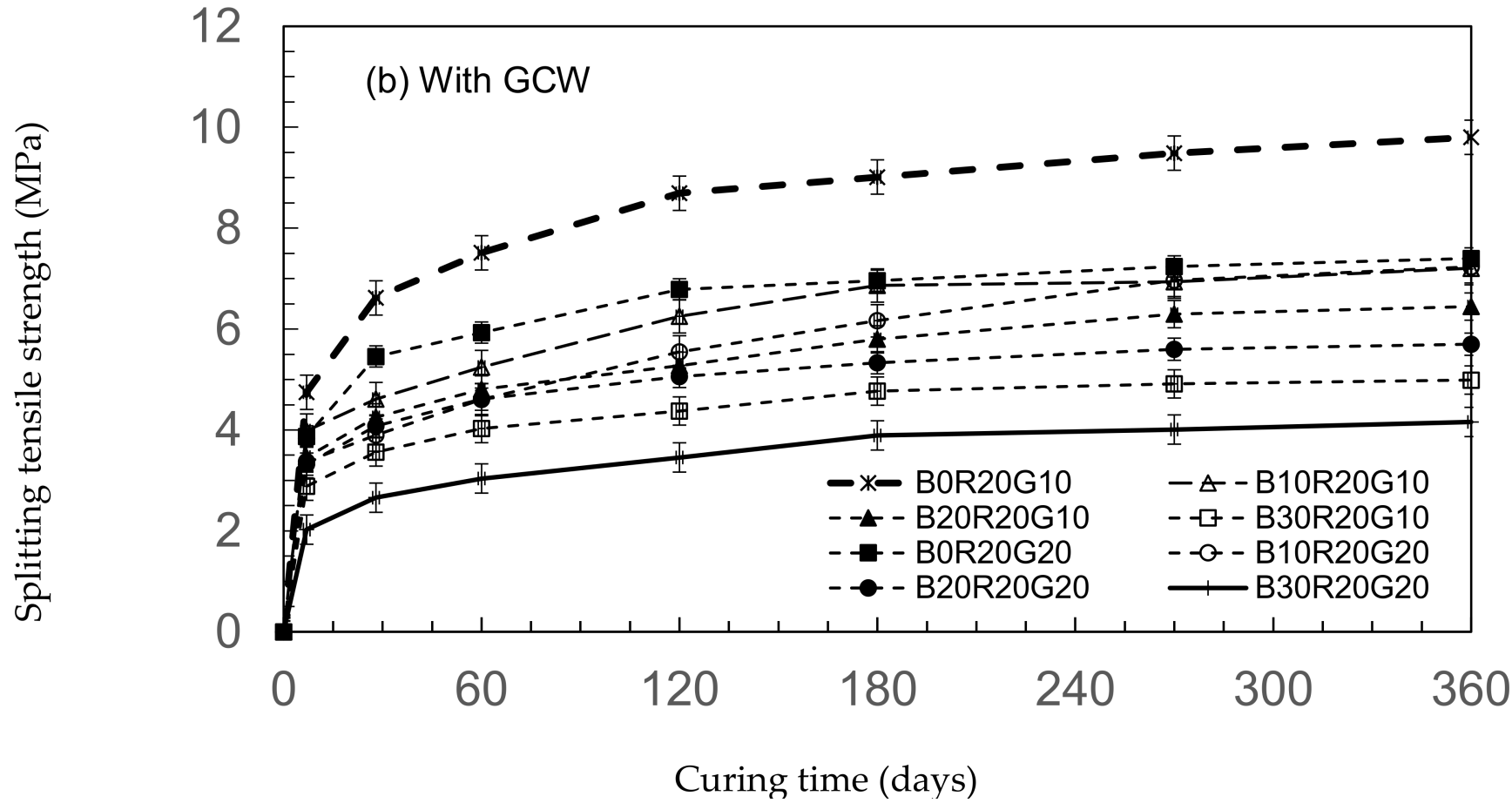

Figure 4. Splitting tensile strengths of gSCC. (a) without GCW and (b) with GCW.

As a proportion of compressive strengths, the splitting tensile strengths for gSCC are indicated in Figure 5. In gSCC, these percentages varied from 8.5 to $15 \%$, which are the same as those of conventional concretes. Beixing et al. [27] noted that the proportions of the concrete splitting tensile strengths integrating BA were in the range of $10-12 \%$ of compressive strength. Additionally, the findings and results reinforce those of previous studies, showing that the plain concretes' splitting tensile strengths were about ten percent of their compressive strengths. The results indicate that the splitting tensile strength increases linearly with increasing compressive strength [36]. 


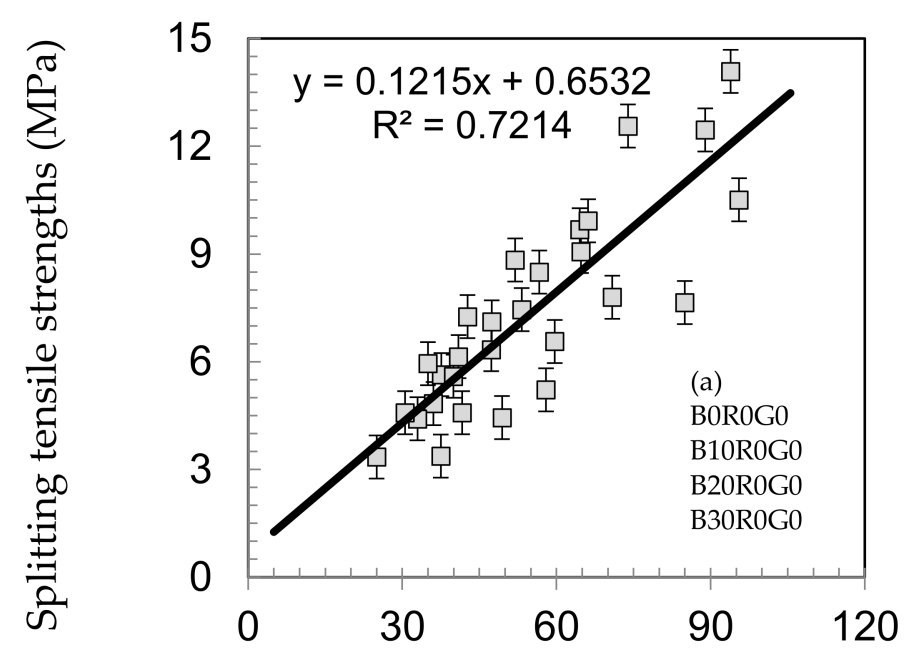

(a) Compressive strength (MPa)

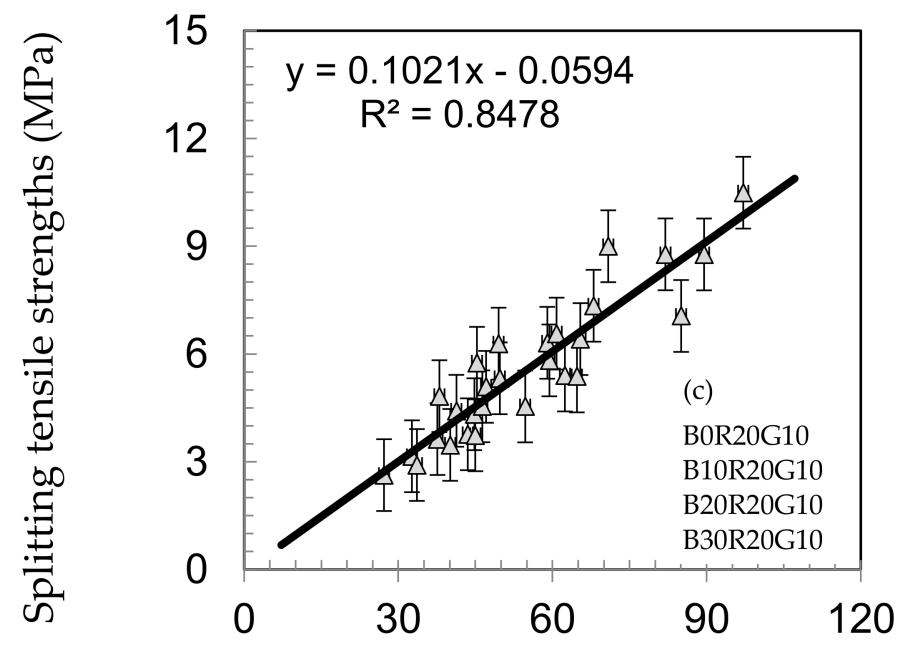

(c) Compressive strength $(\mathrm{MPa})$

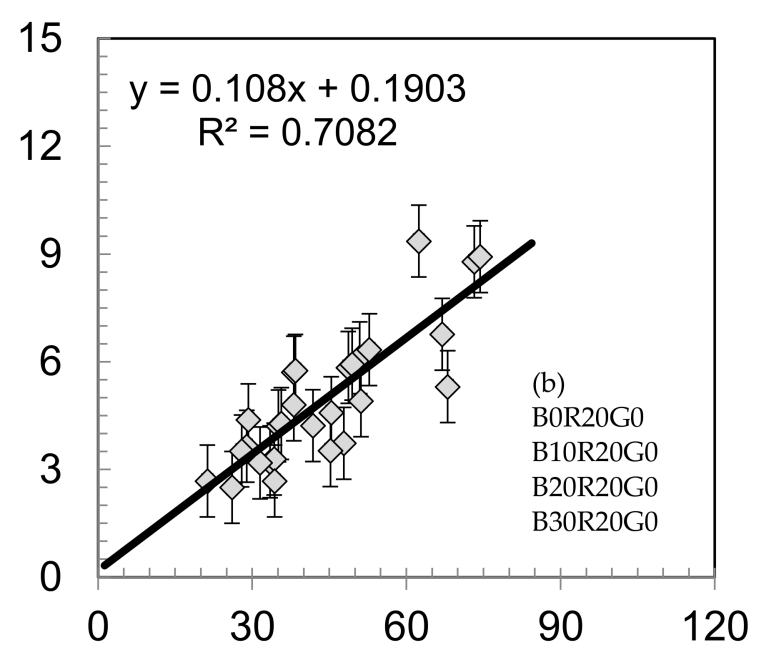

(b) Compressive strength $(\mathrm{MPa})$

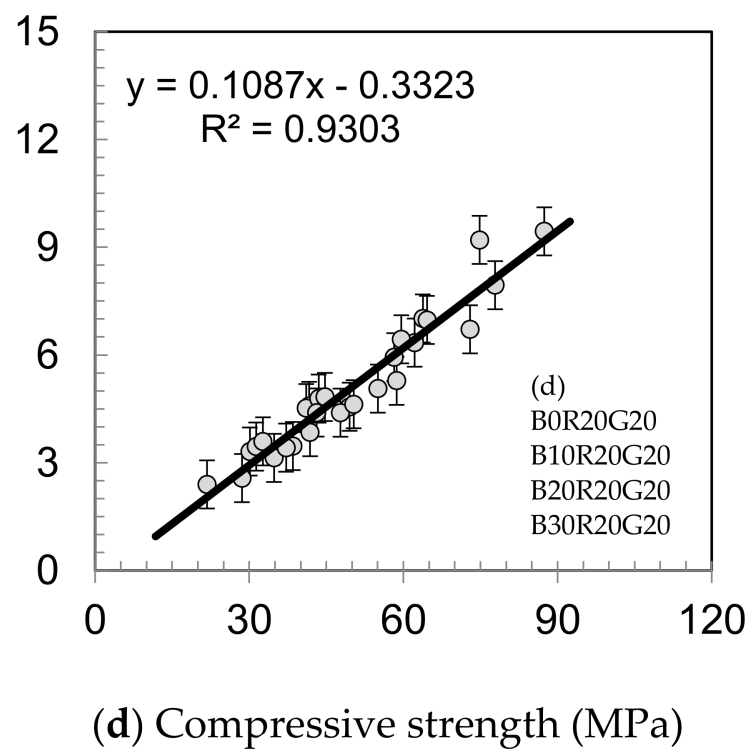

Figure 5. Relationships between splitting tensile strengths as a proportion of compressive strengths of concretes. (a) with BA, (b) with BA+20\%RHA, (c) with BA+20\%RHA+10\%GCW, and (d) with BA+20\%RHA+20\%GCW.

\subsubsection{Moduli of Elasticity (MOE)}

The elasticity moduli of the concretes over 360 days of testing are shown in Figure 6. At 28 days, the elasticity moduli of B0R20G0, B10R20G0, B20R20G0, and B30R20G0 are $27.5,18.2,18.1$, and $14.2 \mathrm{GPa}$, respectively. The elasticity moduli at 360 days are $36.9,32.3$, and 25.5 GPa for B10R20G10, B20R20G10, and B30R20G10, respectively, as shown. The findings show that the elasticity moduli of gSCC with GCW appear to improve with curing ages. Figure 7 shows the relationships between the modulus of elasticity and compressive strength of gSCC. The elasticity moduli were virtually associated with the strengths of the concretes. The results and findings are in accordance with those of the studies of Chen et al. [37] and Chindaprasirt et al. [38]. The scholars noted that the elasticity moduli of concretes having pozzolanic substances, such as virgin pozzolans and fly ashes, appeared to improve with curing age in a similar manner to the moduli of elasticity developments of traditional concretes [38]. 


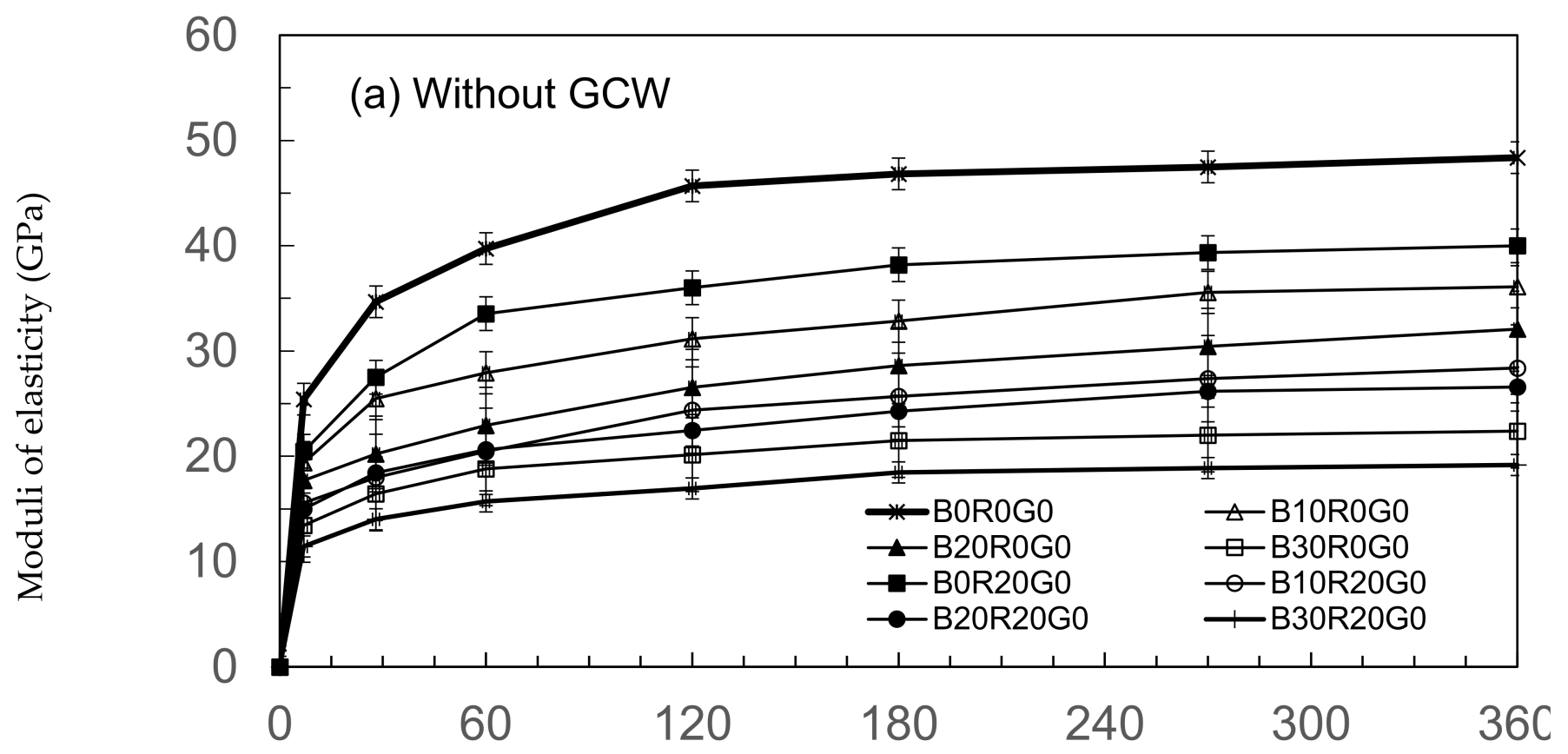

Curing time (days)

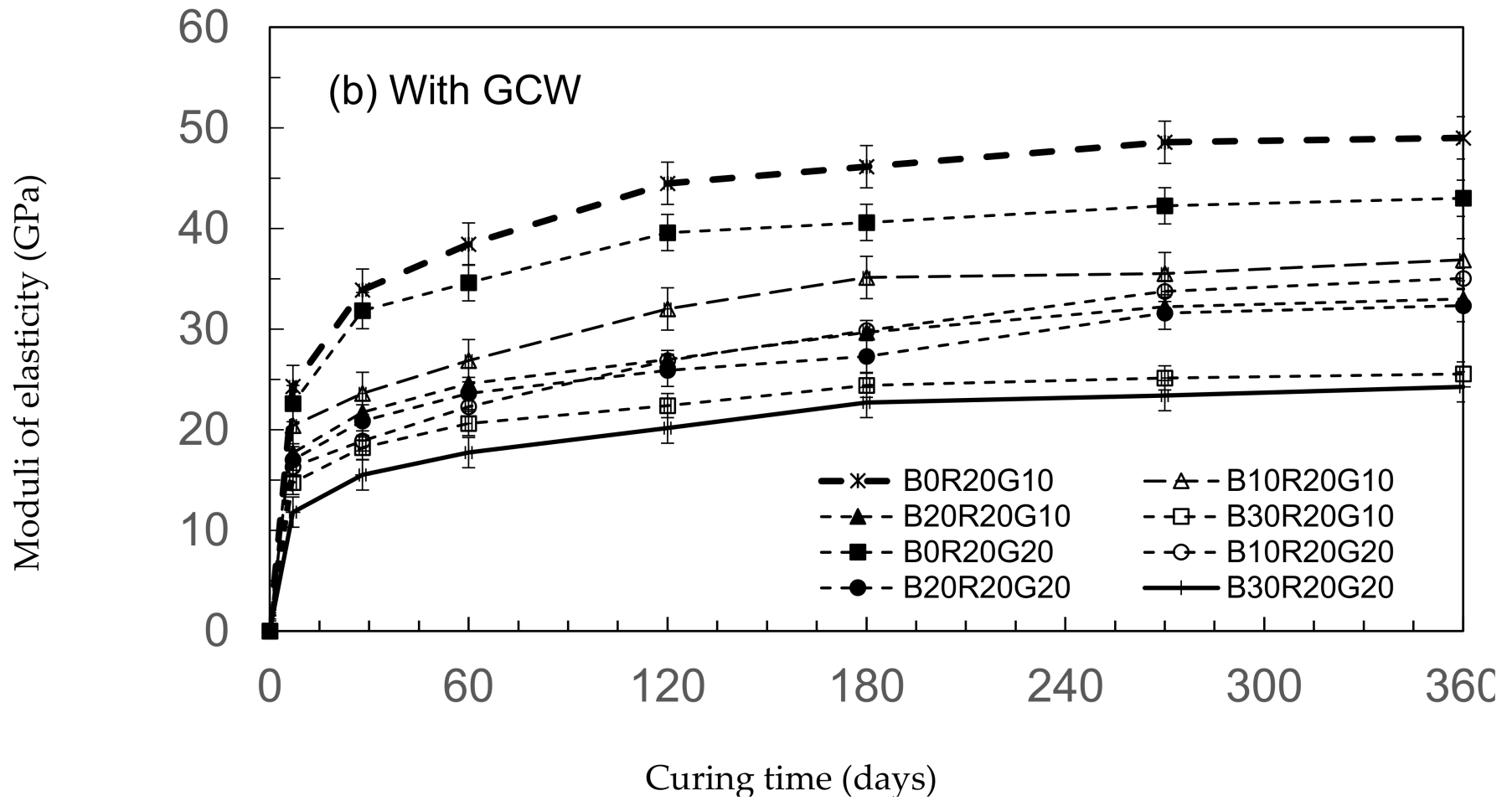

Figure 6. Moduli of elasticity of gSCC. (a) without GCW and (b) with GCW. 


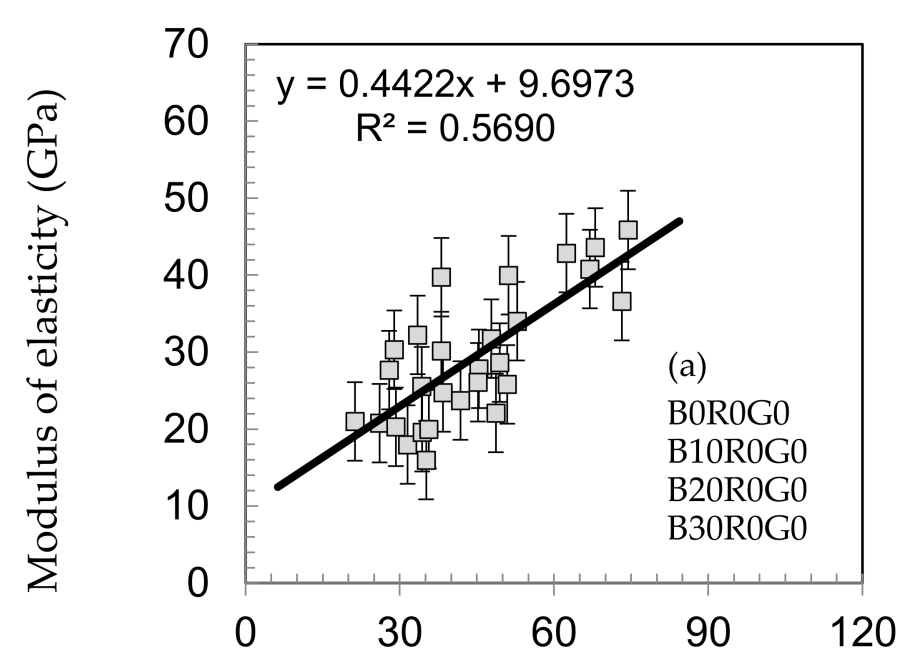

(a) Compressive strength (MPa)

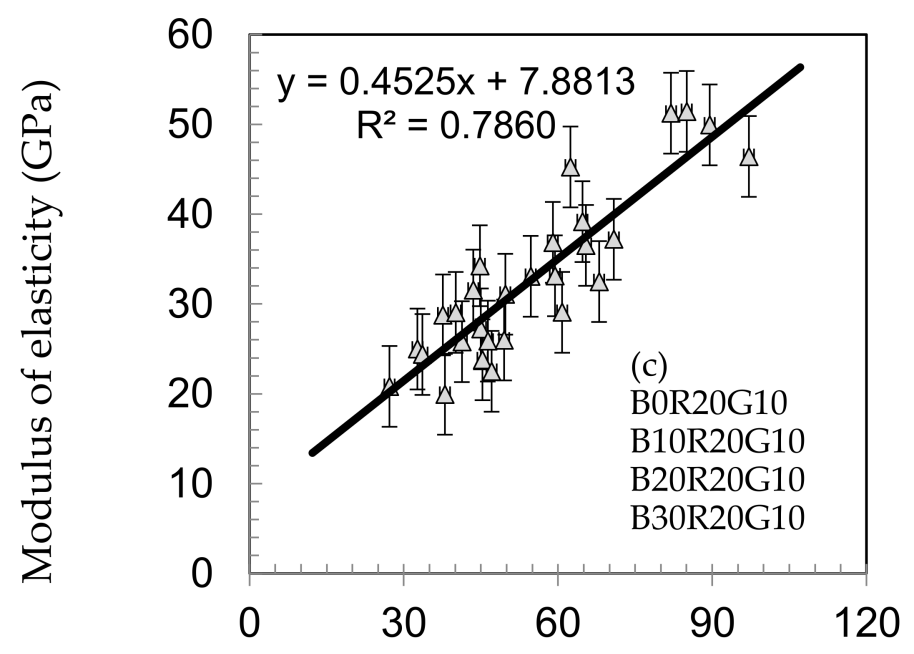

(c) Compressive strength (MPa)

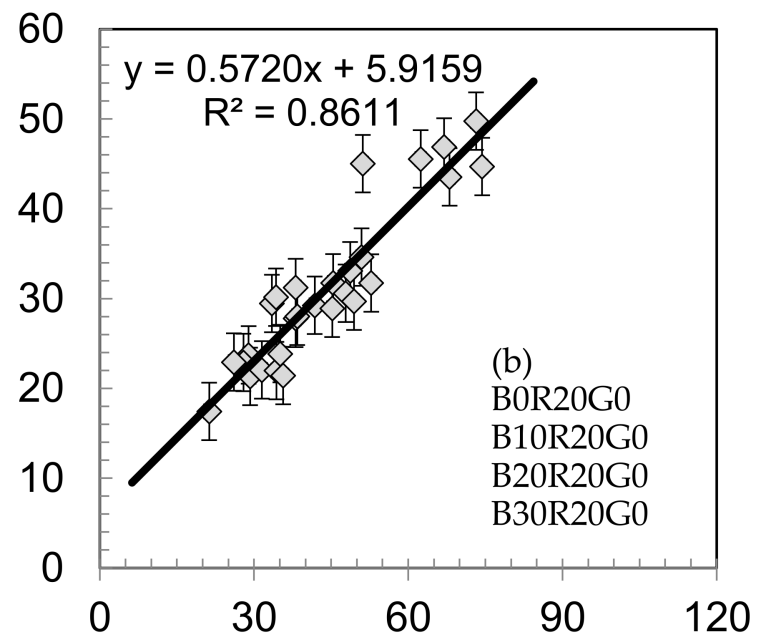

(b) Compressive strength (MPa)

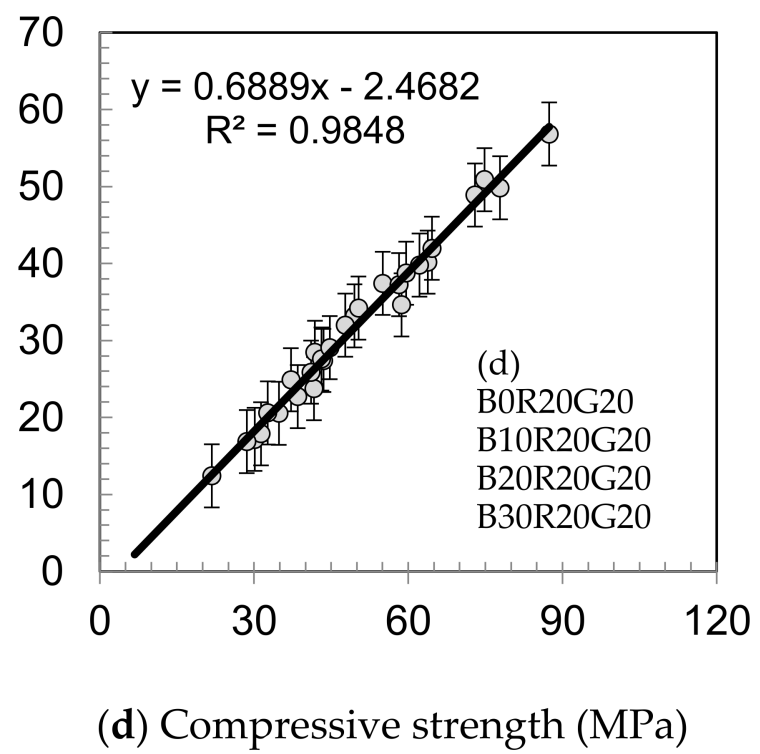

Figure 7. Relationships between the modulus of elasticity and compressive strength of gSCC. (a) with BA, (b) with BA+20\%RHA, (c) with BA+20\%RHA+10\%GCW, and (d) with BA+20\%RHA+20\%GCW.

\section{Optimal Content of GCW}

The gSCC specimens were utilized to establish the optimal percentages of GCW associated with BA and RHA [3]. At a constant of 1:2.15, a binder to aggregate mortars was set by mass as outlined by ASTM C39 [24]. By adjusting the content of water in the gSCC, the flow of gSCC was sustained with the controlled slump flow of a $70.0 \pm 2.5 \mathrm{~cm}$ diameter [13]. The gSCC binder contents were mixtures of BA, RHA, and GCW. The OPC was substituted by BA, RHA, and GCW at percentage replacements of $40 \mathrm{wt} \%$ (B10R20G10) to $70 \mathrm{wt} \%$ (B30R20G20) by mass of the total binder content of $650 \mathrm{~kg} / \mathrm{m}^{3}$. Until the testing stage, the gSCCs were cured in saturated lime water (calcium hydroxide) [39-41]. For each stage, the mean of compressive strengths of mortars was obtained from three samples. The relationships between compressive strengths and the substitution of GCW with OPC in the BA and RHA mixtures at the rates of 10 and $20 \%$ by mass of the total binder contents incorporating BA, RHA, and GCW are presented in Figure 8. It was demonstrated that the 28-day and 360-day compressive strengths of B10R20G10 improved from 10.1 to $33.5 \mathrm{MPa}$ and from 10.2 to $52.8 \mathrm{MPa}$. The optimum ratio of BA plus RHA to GCWs was 67:33 by mass. 
This ratio yielded the greatest compressive strength of $37.6 \mathrm{MPa}$ at 7 days and $43.5 \mathrm{MPa}$ at 28 days.

Compared to gSCC that required $390 \mathrm{~kg} / \mathrm{m}^{3}$ of OPC, the gSCC prepared by $10 \mathrm{wt} \%$ GCW associated with $10 \mathrm{wt} \% \mathrm{BA}$ and $20 \mathrm{wt} \%$ RHA was improved significantly. The filling and passing abilities of the gSCC were improved by using GCW. In addition, the gSCC achieved continuous mechanical development compared to the control SCC, as the binder contents could minimize the consumption of OPC by up to $40 \%$.

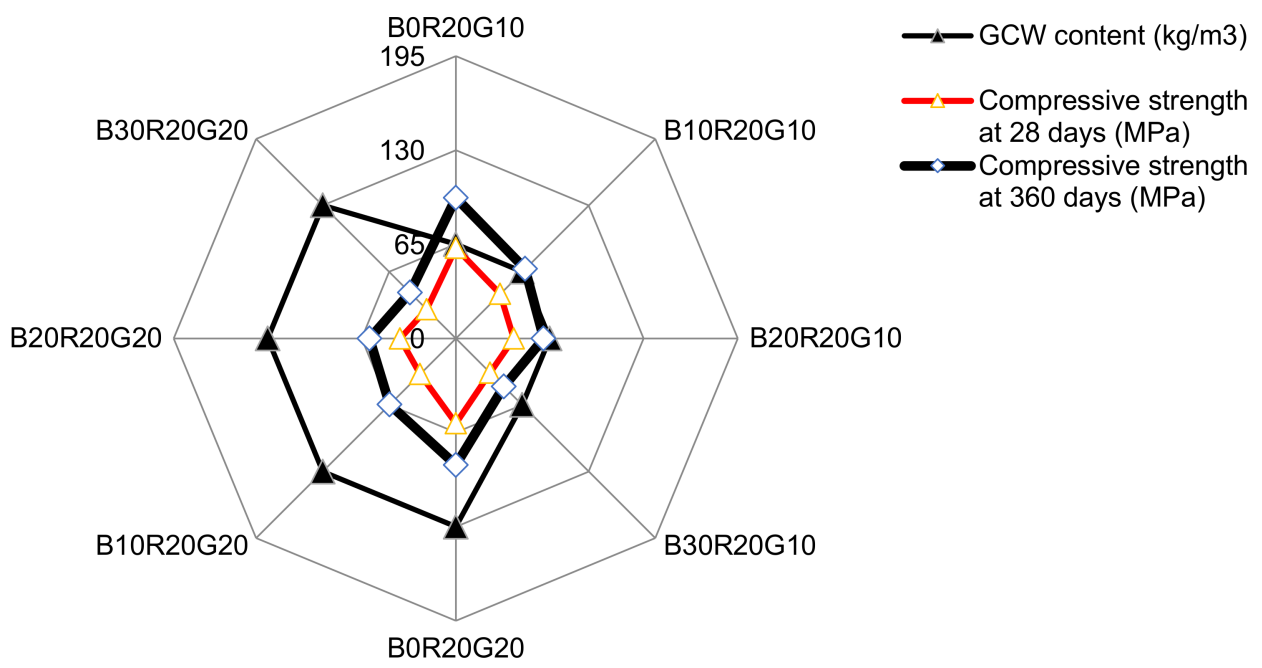

Figure 8. Relationships between compressive strengths of concretes and cement substitution levels of GCW in gSCC mixtures.

At present, there is no economically feasible mineral that can produce manufactured cement with an equivalent quality to that of the present OPC [14]. Researchers have studied the impact of the substitutions by adding minerals to the mechanical features of cements and decreasing the emission of $\mathrm{CO}_{2}$. The investigations state that by decreasing OPC by replacing it with different pozzolanic materials and using raw materials for OPC production, $\mathrm{CO}_{2}$ emissions may easily be decreased [16]. The researchers investigated the energy that contributes to the use of technology to reduce $\mathrm{CO}_{2}$ emissions. They used lifecycle assessing techniques to distinguish the freshly installed and available technology and also the ready-mixed concrete plant. The researchers suggest the potential of computational fluid dynamics (CFDs) to help optimize the suitable mix proportions for gSCC based on the fresh state behaviors and to help reduce $\mathrm{CO}_{2}$ emissions from the production of concrete.

\section{Statistically Descriptive and ANOVA Analyses of the gSCC Mixtures Based on Compressive Strength Development (CSD)}

Table 5 shows the normalized CSD of gSCC mixtures compared to the control SCC. Table 6 shows the results of the single-factor ANOVA analysis of normalized CSD compared to the control SCC (B0R0G0), obtained from Table 5, with the assumptions including a normally distributed population, an equal variance population, and an independently sampled population. Part (a) indicates the influence of BA on gSCC without RHA and GCW, $p$-value $\left(1.86627 \times 10^{-10}\right)<0.01$ at $\alpha=0.05$, which means that the incorporation of an increasing percentage of replacement BA, from 10 to $30 \mathrm{wt} \%$, in OPC yielded a statistically significant difference, indicating a reasonable effect on the CSD of the gSCC. These results can be interpreted similarly to those of the CSD of (b) gSCC containing $20 \mathrm{wt} \%$ of RHA and without GCW $\left(p\right.$-value $\left.\left(3.79911 \times 10^{-8}\right)<0.01\right)$. In addition to the significance of the interpretation of the ANOVA results, the lower replacement amount of BA in OPC yielded a higher CSD, and the lowest CSD of gSCC occurred for the B30R0G0 (without RHA) and B30R20G0 (with RHA) mixtures. 
The influence of the GCW on the properties of the gSCC prepared by BA and RHA are presented in Table 6. Parts (c), (d), and (e), show the influence of GSW in gSCC mixed with 10,20 , and $30 \mathrm{wt} \%$ of $\mathrm{BA}$ and $20 \mathrm{wt} \%$ of RHA, respectively. It was demonstrated that incorporating the GCW in the gSCC mixtures had a significant effect on the CSD up to 360 curing days. For example, the gSCC mixed with 10\% BA and $20 \mathrm{wt} \%$ RHA had a $p$-value $\left(4.90469 \times 10^{-6}\right)<0.01$, resulting in a statistically significant difference, indicating a reasonable effect on the CSD of the gSCC as well as in the mixtures of the gSCC mixed with $20 \%$ BA and $20 \mathrm{wt} \%$ RHA ( $p$-value of $4.66498 \times 10^{-5}$ ) and $30 \%$ BA and $20 \mathrm{wt} \%$ RHA $\left(p\right.$-value of $\left.2.424 \times 10^{-7}\right)$.

Referring to the descriptive meaning of the CSD of the gSCC in Table 6, parts (c), (d), and (e), it was found that the average values of the gSCC mixtures containing $10 \mathrm{wt} \%$ GCW (B10R20G10, B20R20G10 and B30R20G10) had the highest CSD compared to those mixtures mixed with 0 and $20 \mathrm{wt} \%$ GCW. This is due to the filling effect of GCW particles, consistent with a continuous increase in CSD over 360 days. However, the variances of the gSCC mixtures containing $10 \mathrm{wt} \%$ GCW were also higher than those of 0 and $20 \mathrm{wt} \% \mathrm{GCW}$, possibly due to the physical variance effects between the filling effect and the amount of OPC hydration (C-S-H) products, while the $20 \mathrm{wt} \% \mathrm{GCW}$ was affected by a decrease in OPC content, resulting in a lower amount of hydration product.

Compared to the gSCC mixtures containing GCW, the B10R20G10 mixture with $10 \mathrm{wt} \%$ BA, $20 \mathrm{wt} \% \mathrm{RHA}$, and $10 \mathrm{wt} \% \mathrm{GCW}$ in replacement of $40 \mathrm{wt} \%$ of OPC yielded the greatest CSD over 360 days of curing due to the particle filling effect associated with the hydrated level of OPC and the hydration products as mentioned above.

Table 5. Normalized CSD compared to the control SCC (B0R0G0).

(a) gSCCs prepared without GCW

\begin{tabular}{|c|c|c|c|c|c|c|c|c|}
\hline Age Mixture & B0R0G0 & B10R0G0 & B20R0G0 & B30R0G0 & B0R20G0 & B10R20G0 & B20R20G0 & B30R20G0 \\
\hline 0 day & 0.00000 & 0.00000 & 0.00000 & 0.00000 & 0.00000 & 0.00000 & 0.00000 & 0.00000 \\
\hline 7 days & 1.00000 & 0.76276 & 0.69624 & 0.52832 & 0.80533 & 0.61193 & 0.59019 & 0.44963 \\
\hline 28 days & 1.00000 & 0.73490 & 0.58304 & 0.47351 & 0.79332 & 0.51898 & 0.53125 & 0.40411 \\
\hline 60 days & 1.00000 & 0.70308 & 0.57759 & 0.47335 & 0.84439 & 0.51529 & 0.51959 & 0.39547 \\
\hline 120 days & 1.00000 & 0.68225 & 0.58128 & 0.44109 & 0.78817 & 0.53390 & 0.49187 & 0.37090 \\
\hline 180 days & 1.00000 & 0.72832 & 0.59831 & 0.44943 & 0.79861 & 0.53736 & 0.50801 & 0.38617 \\
\hline 270 days & 1.00000 & 0.70458 & 0.60326 & 0.43612 & 0.77934 & 0.54223 & 0.51844 & 0.37397 \\
\hline 360 days & 1.00000 & 0.74173 & 0.62444 & 0.43587 & 0.77852 & 0.55265 & 0.51743 & 0.37324 \\
\hline \multicolumn{9}{|c|}{ (b) gSCCs prepared with GCW } \\
\hline Age Mixture & B0R20G10 & B10R20G10 & B20R20G10 & B30R20G10 & B0R20G20 & B10R20G20 & B20R20G20 & B30R20G20 \\
\hline 0 day & 0.00000 & 0.00000 & 0.00000 & 0.00000 & 0.00000 & 0.00000 & 0.00000 & 0.00000 \\
\hline 7 days & 1.00000 & 0.94688 & 0.79551 & 0.69052 & 0.57553 & 0.88060 & 0.63641 & 0.66290 \\
\hline 28 days & 1.00000 & 0.96784 & 0.67467 & 0.62156 & 0.52130 & 0.90977 & 0.53974 & 0.59670 \\
\hline 60 days & 1.00000 & 0.95880 & 0.66987 & 0.61312 & 0.51411 & 0.86292 & 0.55599 & 0.58859 \\
\hline 120 days & 1.00000 & 0.96493 & 0.69407 & 0.58533 & 0.48588 & 0.85879 & 0.58302 & 0.56192 \\
\hline 180 days & 1.00000 & 0.95587 & 0.72780 & 0.61469 & 0.50588 & 0.84117 & 0.61863 & 0.56551 \\
\hline 270 days & 1.00000 & 0.95312 & 0.69705 & 0.63250 & 0.49364 & 0.82922 & 0.66220 & 0.61985 \\
\hline 360 days & 1.00000 & 1.01657 & 0.71153 & 0.63643 & 0.49267 & 0.91492 & 0.67596 & 0.62371 \\
\hline
\end{tabular}


Table 6. Descriptive and one-way ANOVA analysis results at $\alpha=0.05$ obtained from normalized compressive strength compared to the control SCC (B0R0G0).

(a) Influence of BA in gSCC (without RHA and GCW)

\begin{tabular}{ccccccc}
\hline Mixture & Count & Sum (-) & Average (-) & Variance (-) \\
\hline B10R0G0 & 7 & & 5.057620997 & 0.722517285 & 0.000749467 \\
B20R0G0 & 7 & & 4.264155899 & 0.609165128 & 0.001737440 \\
B30R0G0 & 7 & & 3.237675198 & 0.462525028 & 0.001100864 \\
\hline Source of Variation & SS & df & MS & F & $p$-value & F crit \\
\hline Between Groups & 0.237878676 & 2 & 0.118939338 & 99.4539509 & $1.86627 \times 10^{-10}$ & 3.554557146 \\
Within Groups & 0.021526627 & 18 & 0.001195924 & - & - & - \\
\hline
\end{tabular}

(b) Influence of BA in gSCC mixed with $20 \mathrm{wt} \%$ RHA (without GCW)

\begin{tabular}{ccccccc}
\hline Mixture & Count & Sum (-) & Average (-) & Variance (-) \\
\hline B10R20G0 & 7 & & 3.812343666 & 0.544620524 & 0.001047734 \\
B20R20G0 & 7 & & 3.676774698 & 0.525253528 & 0.000967302 \\
B30R20G0 & 7 & & 2.753489456 & 0.393355637 & 0.000770578 \\
\hline Source of Variation & SS & df & MS & F & $p$-value & F crit \\
\hline Between Groups & 0.094857468 & 2 & 0.047428734 & 51.07894687 & $3.79911 \times 10^{-8}$ & 3.554557146 \\
Within Groups & 103643.7358 & 24 & 4318.488992 & - & - & - \\
\hline
\end{tabular}

(c) Influence of GSW in gSCC mixed with $10 \mathrm{wt} \% \mathrm{BA}$ and $20 \mathrm{wt} \%$ RHA

\begin{tabular}{ccccccc}
\hline Mixture & Count & Sum (-) & Average (-) & Variance (-) \\
\hline B10R20G0 & 7 & & 3.812343666 & 0.544620524 & 0.001047734 \\
B10R20G10 & 7 & & 4.970509880 & 0.710072840 & 0.001818456 \\
B10R20G20 & 7 & & 4.271944572 & 0.610277796 & 0.002737935 \\
\hline Source of Variation & SS & df & MS & F & $p$-value & F crit \\
\hline Between Groups & 0.09717026 & 2 & 0.04858513 & 26.00858778 & $4.90469 \times 10^{-6}$ & 3.554557146 \\
Within Groups & 0.033624753 & 18 & 0.001868042 & - & - & - \\
\hline
\end{tabular}

(d) Influence of GSW in gSCC mixed with $20 \mathrm{wt} \%$ BA and $20 \mathrm{wt} \%$ RHA

\begin{tabular}{ccccccc}
\hline Mixture & Count & Sum (-) & Average (-) & Variance (-) \\
\hline B20R20G0 & 7 & & 3.676774698 & 0.525253528 & 0.000967302 \\
B20R20G10 & 7 & & 4.394147722 & 0.627735389 & 0.001043431 \\
B20R20G20 & 7 & & 4.219173057 & 0.602739008 & 0.001273434 \\
\hline Source of Variation & SS & df & MS & F & $p$-value & F crit \\
\hline Between Groups & 0.039973151 & 2 & 0.019986575 & 18.25720982 & $4.66498 \times 10^{-5}$ & 3.554557146 \\
Within Groups & 0.019705002 & 18 & 0.001094722 & - & - & - \\
\hline
\end{tabular}

(e) Influence of GSW in gSCC mixed with $30 \mathrm{wt} \%$ BA and $20 \mathrm{wt} \%$ RHA

\begin{tabular}{ccccccc}
\hline Mixture & Count & Sum (-) & Average (-) & Variance (-) \\
\hline B30R20G0 & 7 & & 2.753489456 & 0.393355637 & 0.000770578 \\
B30R20G10 & 7 & & 3.589017400 & 0.512716771 & 0.000925573 \\
B30R20G20 & 7 & & 3.180552613 & 0.454364659 & 0.000178851 \\
\hline Source of Variation & SS & df & MS & F & $p$-value & F crit \\
\hline Between Groups & 0.049873018 & 2 & 0.024936509 & 39.89837688 & $2.424 \times 10^{-7}$ & 3.554557146 \\
Within Groups & 0.01125001 & 18 & 0.000625001 & - & - & - \\
\hline
\end{tabular}

Remark: The compressive strengths of control SCC were 47.30, 64.50, 73.90, 84.97, 89.00, 93.90, and 95.54 MPa at 7, 28, 60, 120, 180, 270, and 360 days (Count $=7$ ), respectively.

\section{Conclusions}

Based on the experimental and analysis results from the investigation of using GCW in gSCC production prepared by triple combined GCW (10 and $20 \mathrm{wt} \%)$, low-quality BA 
$(10,20$, and $30 \mathrm{wt} \%)$ and low-quality RHA (20 wt $\%)$, the following conclusions can be made:

- In order to maintain the controlled slump flows of gSCC at a $70.0 \pm 2.5 \mathrm{~cm}$ diameter, the $\mathrm{w} / \mathrm{b}$ ratios of the gSCC mixtures incorporating BA and RHA varied in the range between 0.48 and 0.54 and 0.49 and 0.56 , respectively. The required $\mathrm{w} / \mathrm{b}$ ratios for the gSCC with BA and RHA were greater than those for SCCs without RHA. With BA and RHA incorporating GCW, the gSCC had lower w/b ratios than those without BA and RHA, but had higher $\mathrm{w} / \mathrm{b}$ ratios than the control SCCs.

- When the amounts of GCW increased, the fresh densities of the gSCC mixtures incorporating BA and RHA decreased with a GCW content of $10 \mathrm{wt} \%$. The fresh densities of the gSCC with mixtures of RHA also decreased when increasing the amount of GCW.

- The majority of the mixtures retained acceptable flow times considering the SCC workability. The differences in the levels of GCW substitution and the V-funnel flow results showed general correlations with the increase in GCW. In addition, gSCC prepared by BA needed more $\mathrm{w} / \mathrm{b}$ to sustain similar workability as compared to that of the control SCC.

- The mechanical performance of the gSCC continuously developed in comparison to the control SCC, as the binder contents could minimize the consumption of OPC by up to $40 \%$. The gSCC mixtures of the GCW with BA and RHA as binder decreased the concrete's compressive strength at 360 days.

- The greatest compressive strength was achieved in the mixtures of the gSCC prepared with $10 \mathrm{wt} \% \mathrm{GCW}$ in $10 \mathrm{wt} \% \mathrm{BA}$ and $20 \mathrm{wt} \%$ RHA, which were consistent with descriptive and ANOVA analyses of the gSCC mixtures based on compressive strength development.

- Compared to the gSCC that required $390 \mathrm{~kg} / \mathrm{m}^{3}$ of OPC, the gSCC prepared with $10 \mathrm{wt} \%$ GCW associated with $10 \mathrm{wt} \%$ BA and $20 \mathrm{wt} \%$ RHA was improved, with the properties of workability including filling and passing abilities.

Author Contributions: Conceptualization, P.L.; methodology, N.M. and P.L.; investigation, P.L. and N.M.; data curation, N.M.; writing-original draft preparation, N.M.; writing-review and editing, P.L.; visualization, N.M.; supervision, P.L.; project administration, P.L.; funding acquisition, P.L. All authors have read and agreed to the published version of the manuscript.

Funding: This research was funded by the Thammasat University Research Fund, Contract number TUGR 2/29/2562.

Institutional Review Board Statement: Not applicable.

Informed Consent Statement: Not applicable.

Data Availability Statement: The data presented in this study are available on request from the corresponding author.

Acknowledgments: This study was supported by Thammasat University under research fund No. TUGR 2/29/2562.

Conflicts of Interest: The authors declare no conflict of interest.

\section{References}

1. Kolias, S.; Kasselouri-Rigopoulou, V.; Karahalios, A. Stabilisation of clayey soils with high calcium fly ash and cement. Cem. Conr. Comp. 2005, 27, 301-313. [CrossRef]

2. Chao, L.C.; Kuo, C.P. Ternary blends of high aluminate cement, fly ash and blast-furnace slag for sewerage lining mortar. IOP Conf. Ser. Mater. Sci. Eng. 2018, 303, 12023. [CrossRef]

3. Clark, M.W.; Despland, L.M.; Lake, N.J.; Yee, L.H.; Anstoetz, M.; Arif, E.; Doumit, P. High-efficiency cogeneration boiler bagasseash geochemistry and mineralogical change effects on the potential reuse in synthetic zeolites, geopolymers, cements, mortars, and concretes. Heliyon 2017, 3, e00294. [CrossRef]

4. Hoshino, S.; Negishi, K.; Honda, A. Mechanism of alkalinity lowering and chemical equilibrium model of high fly ash silica fume cement. Concr. Res. Tech. 2014, 25, 97-107. [CrossRef] 
5. Rubin, J.B.; Taylor, C.; Sivils, L.D.; Carey, J.W. Radioactive wastes dispersed in stabilized ash cements. In Proceedings of the International Ash Utilization Symposium, Lexington, KY, USA, 31 December 1997.

6. Mallisa, H.; Turuallo, G. The maximum percentage of fly ash to replace part of original Portland cement (OPC) in producing high strength concrete. AIP Conf. Proc. 2017, 1903, 30012.

7. Makul, N.; Sua-iam, G. Effect of granular urea on the properties of self-consolidating concrete incorporating untreated rice husk ash: Flowability, compressive strength and temperature rise. Constr. Build. Mater. 2018, 162, 489-502. [CrossRef]

8. Makul, N. Combined use of untreated-waste rice husk ash and foundry sand waste in high-performance self-consolidating concrete. Results Mater. 2019, 1, 100014. [CrossRef]

9. Malhotra, V.M.; Mehta, P.K. Pozzolanic and Cementitious Materials; CRC Press: London, UK, 1996.

10. Lertwattanaruk, P.; Sua-Iam, G.; Makul, N. Effects of calcium carbonate powder on the fresh and hardened properties of self-consolidating concrete incorporating untreated rice husk ash. J. Clean. Prod. 2018, 172, 3265-3278. [CrossRef]

11. Sua-Iam, G.; Makul, N. Utilization of coal-and biomass-fired ash in the production of self-consolidating concrete: A literature review. J. Clean. Prod. 2015, 100, 59-76. [CrossRef]

12. Turuallo, G.; Mallisa, H. Using cementitious materials such as fly ash to replace a part of cement in producing high strength concrete in hot weather. IOP Conf. Ser. Mater. Sci. Eng. 2018, 316, 12039. [CrossRef]

13. EFNARC. Specification and Guidelines for Self-compacting Concrete; European Federation of Producers and Applicators of Specialist Products for Structures (EFNARC): Surrey, UK, 2002.

14. Feng, S.; Gong, L.; Cheng, L.; Wang, B.; Wang, L. Radiobiological waste treatment: Ashing treatment and immobilization with cement. In Proceedings of the Seminar on radioactive waste management practices and issues in developing countries, Beijing, China, 10-14 October 1994; pp. 255-260.

15. Genazzini, C.; Zerbino, R.; Ronco, A.; Batic, O.; Giaccio, G. Hospital waste ashes in Portland cement mortars. Cem. Concr. Res. 2003, 33, 1643-1650. [CrossRef]

16. Kerkhoff, B. Effects of Substances on Concrete and Guide to Protective Treatments; Portland Cement Association: Skokie, IL, USA, 2007.

17. ASTM C188. Standard Test. Method for Density of Hydraulic Cement; ASTM International: West Conshohocken, PA, USA, 2017.

18. ASTM C430. Standard Test. Method for Fineness of Hydraulic Cement by the 45- $\mu m$ (No. 325) Sieve; ASTM International: West Conshohocken, PA, USA, 2017.

19. ASTM C150. Standard Specification for Portland Cement; ASTM International: West Conshohocken, PA, USA, 2020.

20. ASTM C618. Standard Specification for Coal Fly Ash and Raw or Calcined Natural Pozzolan for Use in Concrete; ASTM International: West Conshohocken, PA, USA, 2019.

21. ASTM C33. Standard Specification for Concrete Aggregates; ASTM International: West Conshohocken, PA, USA, 2018.

22. ASTM C1611. Standard Test. Method for Slump Flow of Self-Consolidating Concrete; ASTM International: West Conshohocken, PA, USA, 2018.

23. ASTM C1621. Standard Test. Method for Passing Ability of Self-Consolidating Concrete by J.-Ring; ASTM International: West Conshohocken, PA, USA, 2017.

24. ASTM C39. Standard Test. Method for Compressive Strength of Cylindrical Concrete Specimens; ASTM International: West Conshohocken, PA, USA, 2020.

25. ASTM C496. Standard Test. Method for Splitting Tensile Strength of Cylindrical Concrete Specimens; ASTM International: West Conshohocken, PA, USA, 2017.

26. ASTM C469. Standard Test. Method for Static Modulus of Elasticity and Poisson's Ratio of Concrete in Compression; ASTM International: West Conshohocken, PA, USA, 2014.

27. Beixing, L.; Jiliang, W.; Mingkai, Z. Effect of limestone fines content in manufactured sand on durability of low- and high-strength concretes. Constr. Build. Mater. 2009, 23, 2846-2850.

28. Ali, E.E.; Al-Tersawy, S.H. Recycled glass as a partial replacement for fine aggregate in self-compacting concrete. Constr. Build. Mater. 2012, 35, 785-791. [CrossRef]

29. Arel, H.S. The effect of lignosulfonates on concretes produced with cements of variable fineness and calcium aluminate content. Constr. Build. Mater. 2017, 131, 347-360. [CrossRef]

30. Aydın, S.; Aytaç, A.H.; Ramyar, K. Effects of fineness of cement on polynaphthalene sulfonate based superplasticizer-cement interaction. Constr. Build. Mater. 2009, 23, 2402-2408. [CrossRef]

31. Atis, C.D.; Kilic, A.; Sevim, U.K. Strength and shrinkage properties of mortar containing a nonstandard high-calcium fly ash Cem. Concr. Res. 2004, 34, 99-102. [CrossRef]

32. Binici, H.; Aksogan, O.; Cagatay, I.H.; Tokyay, M.; Emsen, E. The effect of particle size distribution on the properties of blended cements incorporating GGBFS and natural pozzolan (NP). Powd. Tech. 2007, 177, 140-147. [CrossRef]

33. Carro-López, D.; González-Fonteboa, B.; Brito, J.D.; Martínez-Abella, F.; González-Taboada, I.; Silva, P. Study of the rheology of self-consolidating concrete with fine recycled concrete aggregates. Constr. Build. Mater. 2015, 96, 491-501. [CrossRef]

34. Chang, J.; Li, Y.; Cao, M.; Fang, Y. Influence of magnesium hydroxide content and fineness on the carbonation of calcium hydroxide. Constr. Build. Mater. 2014, 55, 82-88. [CrossRef]

35. Binici, H.; Temiz, H.; Kose, M.M. The effect of fineness on the properties of the blended cements incorporating ground granulated blast furnace slag and ground basaltic pumice. Constr. Build. Mater. 2007, 21, 1122-1128. [CrossRef] 
36. Bilir, T.; Gencel, O.; Topcu, I.B. Properties of mortars with fly ash as fine aggregate. Constr. Build. Mater. 2005, 93, 782-789. [CrossRef]

37. Chen, J.J.; Kwan, A.K.H.; Jiang, Y. Adding limestone fines as cement paste replacement to reduce water permeability and sorptivity of concrete. Constr. Build. Mater. 2014, 56, 87-93. [CrossRef]

38. Chindaprasirt, P.; Chotithanorm, C.; Cao, H.T.; Sirivivatnanon, V. Influence of fly ash fineness on the chloride penetration of concrete. Constr. Build. Mater. 2007, 21, 356-361. [CrossRef]

39. Yaşar, E.; Atiş, C.D.; Kiliç, A. High strength lightweight concrete made with ternary mixtures of cement-fly ash-silica fume and scoria as aggregate. Turk. J. Eng. Environ. Sci. 2004, 28, 95-100.

40. Antiohos, S.K.; Papadakis, V.G.; Tsimas, S. Rice husk ash (RHA) effectiveness in cement and concrete as a function of reactive silica and fineness. Cem. Concr. Res. 2014, 61-62, 20-27. [CrossRef]

41. Sua-Iam, G.; Makul, N. Properties of Self-Consolidating Concrete with Rice Husk Ash and Calcium Carbonate Powder. ACI Mater. J. 2018, 115, 675-684. 